Rev Biomed 2005; 16:113-137.

\title{
Biología y métodos diagnósticos del dengue.
}

Revisión

Carmen Acosta-Bas ${ }^{1}$, Ivonne Gómez-Cordero² .

${ }^{1}$ Laboratorio de Anticuerpos Monoclonales, ${ }^{2}$ Laboratorio Síntesis de Péptidos, Centro de Inmunoensayo, La Habana, Cuba.

\section{RESUMEN.}

En el mundo actual el diagnóstico del dengue es una de las prioridades en la esfera del diagnóstico dada la alta incidencia de esta enfermedad re-emergente. En este trabajo se revisa el estado actual del conocimiento sobre las características generales del virus dengue (estructura, composición y expresión viral, genoma viral y determinantes antigénicos), se detalla con especial énfasis las proteínas estructurales y no estructurales y su papel en la respuesta inmune, la identificación de los elementos inmunogénicos y la definición de los epítopos de las proteínas involucradas en la respuesta inmunológica contra el dengue. Se presentan las características generales de los ensayos para la detección de antígenos virales y se detalla el desarrollo de las técnicas de aislamiento y tipificación viral así como las técnicas de reacción en cadena de la polimerasa empleadas para la detección del ARN viral y la detección de antígenos mediante técnicas de ELISA, utilizando novedosos métodos de amplificación. Se discuten los antecedentes de los estudios serológicos y las características generales de estos. Del mismo modo se hace referencia a las ventajas y desventajas de las técnicas de diagnóstico serógico disponibles en sus diferentes formatos. Se analizan las nuevas tendencias en el desarrollo de nuevos métodos de diagnóstico, basados en la tecnología recombinante y la síntesis química, con el objetivo de incrementar la sensibilidad y especificidad de los ensayos para la detección de anticuerpos específicos. (Rev Biomed 2005; 16:113-137)

Palabras clave: Dengue, diagnóstico de dengue, respuesta inmunológica, epidemiología.

\section{SUMMARY.}

Biology and diagnostic methods for dengue.

At present the diagnosis of dengue is one of the priorities in the sphere of diagnosis, due to the high incidence of this re-emerging disease. In this work a review is done on the current state of knowledge about the general characteristics of the virus dengue (its structures, composition and viral expression, viral genome and antigenic determinants). The structural and not structural proteins are detailed with a special emphasis, as well as their role in the immune response, the identification of the immunogenic elements and the definition of the epitopes of proteins involved in the immunologic response against dengue. The general characteristics of the assays for the detection of viral

Solicitud de sobretiros: Carmen Acosta-Bas, Centro de Inmunoensayo, Calle 134 y Ave 25, Apdo 6653, Cubanacán, Playa. Ciudad de la Habana, Cuba.

Tel.: (537) $2082929 . \quad$ Fax: (537) $336514 \quad$ E-mail: iqmonoclo@cie.sld.cu

Recibido el 21/Abril/2004. Aceptado para publicación el 17/Enero/2005.

Este artículo está disponible en http://www.uady.mx/sitios/biomedic/revbiomed/pdf/rb051626.pdf

Vol. 16/No.2/Abril-Junio, 2005 


\section{Acosta-Bas, I Gómez-Cordero.}

antigens are presented and the development of isolation techniques and viral typification are detailed, as well as polymerase chain reaction techniques used for the detection of viral RNA and antigens, by means of ELISA techniques, using novel amplification methods. This paper discusses the antecedents of the serologic studies and the general characteristics of them. In the same way this work deals with the advantages and disadvantages of the serologic diagnosis techniques available in their different formats. Tendencies in the development of new diagnostic methods, based on the recombinant technology and chemical synthesis, are analyzed with the objective of increasing the sensitivity and specificity of the assays used for the detection of specific antibodies.

(Rev Biomed 2005; 16:113-137)

Key words: Dengue, PCR, diagnosis of dengue, inmmunologic response, epidemiology.

\section{Introducción.}

El dengue es un flavirirus que forma parte de la familia Flaviviridae, la que también reagrupa a los pestivirus y a el virus de la hepatitis C (1). Los flavivirus son 68 virus, mayoritariamente transmitidos por artrópodos (arbovirus). Gran número de ellos son patógenos al hombre, por lo que son los causantes de problemas de salud pública. La diversidad de las patologías (fiebre hemorrágica, formas con choque, encefalitis, formas pseudogripales), se caracteriza por su carácter masivo en las epidemias (2). La situación epidemiológica actual (aparición de la forma hemorrágica del dengue en las Américas después de 10 años) explica nuestro interés desde el punto de vista de los servicios de la salud pública (3).

En este trabajo discutiremos los métodos para el diagnóstico del dengue empleando diferentes fuentes de antígeno (proteínas recombinantes y sintéticas). Estos antígenos deberán seleccionarse sobre la base del estudio de las moléculas dianas de la respuesta inmune; el análisis de la estructura tridimensional de estas moléculas y la identificación de zonas submoleculares susceptibles de inducir una respuesta de anticuerpos. Se abordará la organización genética del virus y las estrategias de desarrollo de los diferentes métodos de diagnóstico.

\section{Situación actual.}

El dengue clásico, junto con sus formas más graves, la fiebre hemorrágica por dengue (FHD) y el síndrome de choque por dengue (SCD), han tenido un alcance mundial, pero su surgimiento como un importante problema de salud pública ha sido muy notable en las Américas, donde desde 1989 a 1993 el número de casos aumentó 60 veces en comparación con el quinquenio anterior (3-7).

Con respecto a la incidencia de este arbovirus, en menos de 20 años, la región se ha transformado de hipoendémica a hiperendémica en muchos países de las zonas tropicales del continente americano, con varios serotipos del virus en circulación (8-10).

Anualmente, se presentan más de 50 millones de casos en el mundo, de los que aproximadamente 400,000 son de dengue hemorrágico y 25,000 fallecen a causa de esta enfermedad. En el hemisferio occidental las epidemias de dengue durante los últimos 200 años han ocurrido periódicamente y en los últimos 20 su transmisión y la frecuencia en las epidemias han aumentado considerablemente en la mayoría de los países, sobre todo en las áreas tropicales de las Américas $(5,11,12)$. En la actualidad, la enfermedad se extiende también a muchos países tropicales de Asia y África, en muchos de ellos con un comportamiento endémico $(5,13,14)$. La FHD ha surgido produciendo epidemias en muchos países de la región $(10,12)$.

La Organización Mundial de la Salud (OMS) estima que este virus constituye una amenaza para el $40 \%$ de la población mundial (aproximadamente 2,500 millones de personas) que habitan en más de 100 países tropicales y sub-tropicales expuestos al dengue (5, 10-12, 15-21). En 1998, la OMS consideró al dengue, como la décima causa de muerte en el mundo por enfermedades infecciosas (22). Los menores de 15 años son las principales víctimas de este padecimiento (aproximadamente $95 \%$ de infecciones) (10).

\section{Revista Biomédica}




\section{Biología y diagnóstico del dengue.}

\section{Epidemias de dengue.}

Las primeras epidemias informadas de fiebre del dengue ocurrieron en 1779-1780 en Asia, África, y América del Norte; la ocurrencia simultánea de erupciones en tres continentes indica que estos virus y su vector han tenido una distribución mundial en los trópicos. Durante ese tiempo, la fiebre del dengue fue considerada benigna, con intervalos largos (10-40 años) entre las epidemias mayores (23). Una pandemia global de dengue comenzó en el Sudeste de Asia después de la Segunda Guerra Mundial. Hasta la década de 1960, casi todos los brotes de la enfermedad fueron a intervalos de uno o más decenios y posteriormente se acortaron.

La primera epidemia de dengue clásico de las Américas documentada en laboratorios, fue con el serotipo 3 y afectó a la cuenca del Caribe y a Venezuela en 1963-1964. Anteriormente sólo se había aislado el virus de dengue 2 en Trinidad en 19531954, en una situación no epidémica. En 1968-1969 en otra epidemia en varias islas del Caribe se aislaron los serotipos 2 y 3 (23-27).

En la década de 1970, Colombia se vio afectada por brotes de los serotipos 2 y 3 , que se hicieron endémicos en el Caribe. En 1977, se introdujo en las Américas el serotipo de dengue 1, que inicialmente se detectó en Jamaica y se propagó a la mayoría de las islas del Caribe, causando brotes explosivos. Brotes similares se observaron en Sudamérica septentrional, América Central y México. La transmisión autóctona del dengue 1, durante la segunda mitad de 1980, fue también documentada en el estado de Texas, EUA. En este período se notificaron cerca de 702,000 casos de dengue. En Cuba el $42 \%$ de sus 10 millones de habitantes se infectaron con el dengue 1 (23-27).

En la década de 1980, la magnitud del problema del dengue en las Américas aumentó considerablemente, caracterizándose por una marcada propagación geográfica de la actividad de esta enfermedad en la región (23-27).

El dengue en su forma hemorrágica fue descrito por primera vez en Filipinas, en 1953. Dos años más tarde en Bangkok (Tailandia) y en las tres décadas siguientes, en Camboya, China, India, Indonesia, Laos,
Malasia, Sri Lanka y Viet Nam (10).

Desde el punto de vista epidemiológico, los países de América Latina se encuentran en la misma situación en que estaban hace dos ó tres décadas varios países asiáticos: con epidemias a repetición cada 3-5 años y con un progresivo aumento del número de casos de FHD, particularmente en países de América central (10).

La rápida expansión de grandes centros urbanos, la ausencia de políticas adecuadas de gestión del agua, la propagación del virus por intermedio de viajes e intercambios internacionales, así como la ineficacia de los programas de lucha antivectorial (cuando éstos existen), se encuentran entre los factores que explican la re-emergencia de esta enfermedad en el sud-este asiático, en las islas del Pacífico occidental, en África, en la región oriental del mar Mediterráneo y en América Latina (10).

El impacto del dengue y del dengue hemorrágico es enorme y representa una significativa carga económica sobre la comunidad afectada, que se expresa en: pérdida de vidas sin distinción de edad, sexo o estrato social; gastos para la familia por hospitalización del paciente; pérdida del trabajo; gastos considerables para los municipios en programas para controlar al mosquito; interrupción de los servicios de atención de salud; impacto en la economía en términos de pérdida del turismo $(16,17)$.

\section{Virus del Dengue.}

El virus del Dengue es el principal arbovirus causante de enfermedad del dengue en los humanos, que es una viriosis aguda y sistémica, de transmisión vectorial, re-emergente (10). El período de incubación es de 3 a 14 días, por lo general es de 7 a 10. El hombre, junto con el mosquito, pueden constituir un reservorio en Asia y en África (8,18-20, 22,23,25,28).

\section{El vector y modo de transmisión del virus.}

Es transmitida al humano a través de la picadura de la hembra hematófaga de los mosquitos Aedes (aegypti y albopictus) $(29,30)$. Se conocen además, otras variedades de Aedes: Ae. aegypti var. formosus y Ae. aegypti var. queenslandensis). Ae. albopictus, 


\section{Acosta-Bas, I Gómez-Cordero.}

Ae. polyniensis y otras especies del complejo Ae. scutellaris han sido incriminados como responsables de epidemias, pero menos eficientes que A. aegypti (10).

La especie aegypti es la más distribuida en el mundo (31). Su distribución geográfica abarca una extensa franja tropical y subtropical, entre Estados Unidos, toda América hasta Argentina. Se encuentra en cerca de 100 países tropicales, y cubre la mayor parte de África, Medio Oriente, Sudeste asiático, norte de Australia, e incluso algunas zonas de Europa (5, 8, 25, 28).

Es un vector muy eficiente para transmitir los virus dengue, es antropofílico y vive en la proximidad del hábitat humano. Las invasiones del vector ocurren durante el verano y se considera a los mosquitos en su fase de adulto no sobreviven al invierno con frío intenso. Generalmente se encuentra entre las latitudes $35^{\circ} \mathrm{N}$ y $35^{\circ} \mathrm{S}$ y usualmente no se le encuentra por encima de 1,000 $\mathrm{m}$ de altitud, sin embargo ha sido reportado a 2,121 m en India y a 2,200 en Colombia, incluso a 2,400 $\mathrm{m}$ en Eritrea. Un factor que dificulta su erradicación es el hecho que los huevos de este mosquito pueden resistir largos períodos de desecación (hasta más de un año) (10).

En los años 50 y 60, la Organización Panamericana de la Salud (OPS) llevó a cabo un programa para evitar la fiebre amarilla urbana, logrando en la mayoría de los países la erradicación del Aedes aegypti. Pero en la década de los años 70 comenzó el deterioro del control, reinfectándose sucesivamente los países, hasta que en 1998 el panorama de distribución del vector era similar al que existía antes del inicio de la campaña continental (17).

La dinámica de transmisión del virus está determinada por la interacción entre el ambiente y que estén presentes de forma simultánea: el virus, el vector y el huésped susceptible $(5,22,32)$.

\section{Epidemiología.}

Una epidemia de dengue requiere la presencia de: 1) el mosquito vector generalmente (Aedes aegypti), 2) el virus y 3 ) un gran número de personas susceptibles. Los brotes pueden ser explosivos o progresivos, dependiendo de la densidad y susceptibilidad del vector, la cepa del virus de dengue, el nivel de inmunidad en la población humana, y la intensidad de contacto vector-humano $(5,12)$.

En la reciente epidemiología de la enfermedad se han observado cambios drásticos en el incremento de la morbilidad-mortalidad y la expansión geográfica, aparentemente asociados con aquéllos que ocurren a los niveles bio-climático, socio-demográfico y de conducta, que a su vez pueden llevar a una mayor circulación viral, a su virulencia y una mayor resistencia vectorial (28).

\section{Clasificación de la infección.}

Según la OMS, la infección por el virus de Dengue puede clasificarse en (34):

- Primaria: se presenta en individuos que se exponen en contacto por primera vez con alguno de los serotipos, los títulos de anticuerpos generalmente no exceden de 1:1280 y son relativamente monoespecíficos.

- Secundaria: se presenta en individuos que se ponen en contacto con otro serotipo del virus. En este caso los títulos de anticuerpos son usualmente mayores de 1:1280 y son heterólogos.

\section{Taxonomía del virus del dengue.}

El dengue es una enfermedad vectorial, provocada por el virus del mismo nombre, que pertenece a $(10,30,33)$ :

- familia Flaviviridae

- género Flavivirus

- $\quad$ especie Dengue

\section{Genómica y factores de virulencia del virus del dengue.}

El virión maduro tiene tres proteínas estructurales: la proteína $\mathrm{C}$ de la nucleocápside, la proteína $\mathrm{M}$, asociada a la membrana y la proteína $\mathrm{E}$ de la envoltura y otras proteínas no estructurales: NS1, NS2A, NS2B, NS3, NS4A, NS4B y NS5. Todas estas proteínas se forman a partir de una gran poliproteína (5' C-prM-E-NS1-NS2A-NS2B-NS3NS4A-NS4B-NS5 3'), para la cual codifica el genoma

\section{Revista Biomédica}




\section{Biología y diagnóstico del dengue.}

del virus $(34,35)$. El genoma del virus está constituido por una molécula de ácido ribonucleico (ARN) de cadena única y aproximadamente 11 kilobases $(\mathrm{kb})$ y de relativamente alta variabilidad genómica. Tiene un coeficiente de sedimentación de $42 \mathrm{~S}$ y un peso molecular de 4,2 kD. El ARN genómico es de polaridad positiva y funciona como $A R N$ mensajero al traducirse directamente en los ribosomas durante el proceso de replicación. Presenta una caperuza tipo I, con una estructura Gppp Amp cubriendo el extremo $5^{\prime}$ terminal, seguido por una secuencia dinucleotídica conservada AG. El extremo 3' terminal carece de cola poliadenilada y termina con una secuencia dinucleotídica conservada $\underline{\mathrm{CU}}(10,18,30,34-37)$.

Los ácidos nucléicos genómicos, por sí mismos, son infecciosos, por lo que las autoridades de salud recomiendan manejar este virus en el nivel de bioseguridad 2 (BLS-2, por sus siglas en inglés) (18, $30,35,37)$.

\section{Proteínas estructurales y no estructurales.}

El genoma contiene un único marco de lectura abierto (MLA) de más de 10,000 bases, flanqueado por las regiones no codificantes (RNC) en ambos extremos ( $3^{\prime}$ y $\left.5^{\prime}\right)$, que codifica para un precursor polipeptídico, que por sucesivos cortes proteolíticos, genera la formación de las 10 proteínas virales a través de un procesamiento co y postraduccional $(10,30$, $35,37)$.

Los genes que codifican las tres proteínas estructurales, núcleo $(\mathrm{C}), \mathrm{prM}$ (el precursor a la membrana), membrana (M), y envoltura (E), están localizados hacia el extremo amino terminal (5') ocupando la cuarta parte de la capacidad codificadora del ARN viral (37). Hacia el extremo carboxilo terminal (3') se encuentran los genes que codifican la información de las siete proteínas no estructurales NS1, NS2a, NS2b, NS3, NS4a, NS4b, NS5 (figura 2) $(10,30,35-38)$.

El orden de las diferentes regiones del gene en el virus es el siguiente (10):

5'NTR-C-prM(M)-E-NS1-NS2A-NS2B-NS3NS4A- NS4B-NS5-3'.NTR.

La ruptura de las uniones C-prM, prM-E, E-

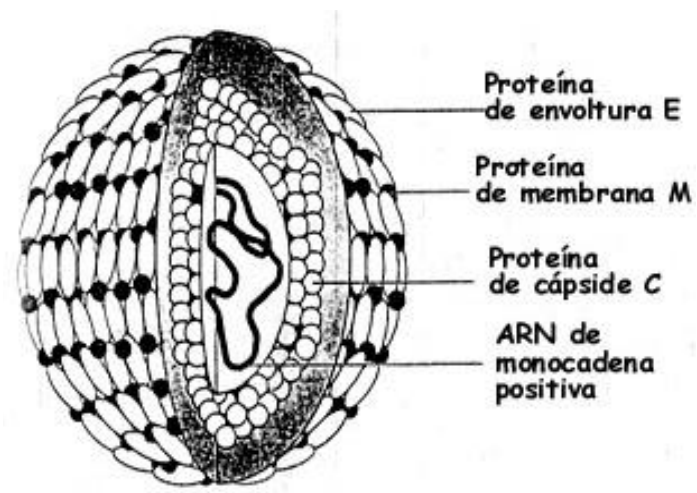

Figura 1.- Virus del Dengue.

NS1, y NS4A-NS4B es realizada por la enzima signalasa retículo endoplásmica (37).

\section{Proteínas virales.}

\section{Proteínas estructurales.}

El virión maduro contiene 3 proteínas estructurales: C, proteína de la nucleocápside o núcleo; $\mathbf{M}$, proteína asociada a la membrana y $\mathbf{E}$, proteína de la envoltura. Los virus inmaduros contienen una proteína conocida por prM; que es un precursor de M (34-38).

La proteína $\mathbf{C}$ es componente básico de la nucleocápside, el primer polipéptido viral sintetizado durante la traducción, tiene un peso molecular de 13.5 $\mathrm{kd}$. Es rica en residuos de lisina y arginina los que le confieren un carácter altamente básico que permite su interacción con el ARN viral, con el que forma la nucleocápside como componente estructural $(34,38)$.

La prM (22 kb) es el precursor glicosilado de la proteína estructural $\mathrm{M}(8 \mathrm{~kb})$. La separación proteolítica de este precursor por una proteasa del aparato de Golgi, durante la maduración viral, es lo que da origen a la formación de la proteína M. Esta

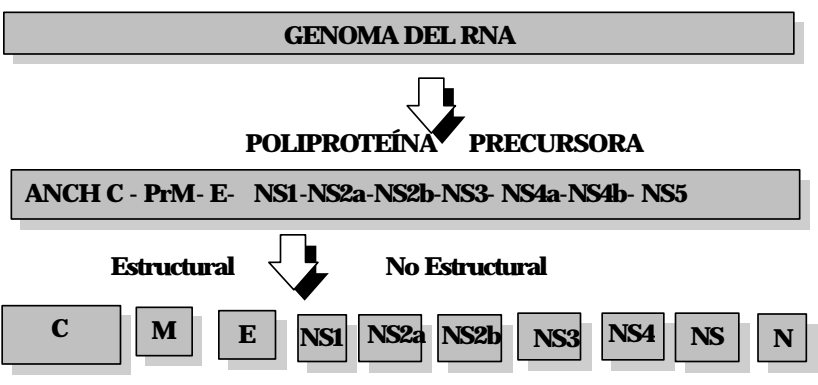

Figura 2.- Organización del genoma viral del Dengue. Vol.16/No.2/Abril-Junio, 2005 


\section{Acosta-Bas, I Gómez-Cordero.}

escisión parece estar ligada a la liberación del virus, pero no ocurre necesariamente en todas las moléculas proteicas presentes en la membrana viral, ya que en ocasiones aparece la proteína M junto a la prM en el virión maduro. Anticuerpos contra prM pudieran mediar inmunidad de tipo protectora, quizás por la neutralización de los viriones liberados que contienen prM no cortada.

Existe en 2 formas, dependiendo de la maduración del virus (38):

Proteína pre-M (prM): Célula-asociada o viriones inmaduros, glicosilada.

Heterodimeriza con proteína E: esencial para el propio plegamiento de $\mathrm{E}$.

La proteína $\mathbf{M}$ madura, es una proteína de membrana, extracelular o de virus maduros, resultado de la proteólisis de prM y eliminación de la porción amino terminal, C-terminal no-glicosilado (38). Está estrechamente asociada a la envoltura lipídica.

La formación de $\mathrm{M}$ a partir de prM parece ser crucial en la morfogénesis del virus, lo que implica un incremento en la infectividad y la reorganización de la estructura de la superficie viral (34). Hasta el presente el papel de $\mathrm{M}$ en el virión no es bien conocido.

La proteína $\mathbf{E}$, es una glicoproteína con un peso molecular entre 51 y $60 \mathrm{kD}$, es la mayoritaria de la envoltura, glicosilada y la más conservada, la fusión con la célula huésped es inducida por pH bajo. Están estrechamente asociada a la envoltura lipídica $(2,34)$.

Se presenta como un homodímero en la superficie del virión maduro e intracelularmente se puede encontrar como un heterodímero junto a la proteína prM en forma de prM-E (34). Es el componente principal de las proyecciones de la superficie del virión observadas por microscopía electrónica y contiene los determinantes antigénicos responsables de la neutralización del virus y la hemaglutinación de eritrocitos de ganso, induciendo respuesta inmunológica en el huésped infectado. Los determinantes de la proteína E están también involucrados en la unión de los viriones a los receptores celulares y probablemente juegan un papel importante en la fusión intraendosomal a pH bajo (34, 37-40). Se ha propuesto que en ella están localizados la mayoría de los marcadores moleculares para la patogenicidad (35-38).

La comparación de la secuencia nucleotídica del gen de la proteína $\mathrm{E}$ de los diferentes flavivirus ha mostrado una conservación perfecta de los 12 residuos de la cisteína, los cuales forman 6 puentes disulfuro. El modelo estructural para la proteína $E$ fue refinado por Mandl y colaboradores, quienes correlacionaron las propiedades estructurales de diferentes epítopos con los puentes disulfuro (41).

\section{Proteínas no estructurales.}

Las siete proteínas virales no estructurales (NS) fueron identificadas y se confeccionaron mapas del ARN viral deducido por la secuencia aminoacídica.

La primera proteína no estructural (NS1), es una glicoproteína de $48 \mathrm{kD}$; que contiene 2 señales del tipo Asn -X-Ser/Thr, usada para la adición de carbohidratos, estos sitios parecen estar conservados en todos los flavivirus. Puede estar en forma secretada y no secretada (38).

Es sintetizada en el retículo endoplásmico rugoso como una proteína monomérica y en un período corto se une formando un homodímero. Esta forma es más hidrofóbica y se desconoce si el incremento de la hidrofobicidad es un resultado de la dimerización o alguna modificación postraduccional. Una vez formado este dímero, la glicoproteína es transportada al aparato de Golgi donde sufre modificaciones y de aquí pasa a la superficie celular, liberándose al medio extracelular (34). Estudios de mutagénesis en la región C terminal de NS1, han demostrado que esta región es importante en la estabilidad y la secreción del dímero (42).

La función de la NS1 en la replicación viral no ha sido bien dilucidada. Se ha planteado que posee un papel en la replicación temprana. Basada en análisis mutacional se ha relacionado con la morfogénesis viral. A su vez, mutaciones de esta proteína afectan la virulencia de la partícula viral (43). También se relaciona con la respuesta inmune específica de serotipo $(22,38)$.

La célula infectada expresa la proteína en la superficie celular, siendo diana de la citolisis

\section{Revista Biomédica}




\section{Biología y diagnóstico del dengue.}

inmunológica, resultando interesante su uso potencial en la protección del hombre contra la infección por flavivirus (44).

La proteína NS1 porta 2 ó 3 sitios de glicosilación en las especies virales, induce una inmunidad protectora y además, aporta epítopos específicos de grupo y de tipo. En los virus de la encefalitis transmitida por garrapata las dos formas de la NS1 están asociadas a secuencias parciales de NS2a (45-47).

Se tiene el consenso que la NS1 induce inmunidad y que la inmunogenicidad es verdaderamente dependiente de la estructura conformacional de la molécula. La forma dimérica es más antigénica que la forma monomérica, pero se ha observado que es destruida por el calor. Las enzimas y los $\mathrm{pH}$ ácidos que solamente participan en la reducción de puentes de disulfuro (48-50). Los anticuerpos inducidos por esta proteína son esencialmente líticos en presencia del complemento y dan la posibilidad de retardar la infección viral en los tejidos (51). Por el contrario, la estimulación de las células $T$ citotóxicas no ha podido ser demostrada hasta el presente.

Huang y colaboradores en 1999 demostraron un reconocimiento cercano al $45 \%$ por anticuerpos de pacientes a un péptido sintético de los 15 primeros aminoácidos de la proteína correspondientes a una región inmunodominante de la NS1. Durante un estudio dinámico, se pudo constatar que a los dos días del comienzo de los síntomas en una infección secundaria, es posible detectar anticuerpos contra este péptido (52).

En un trabajo publicado por García y colaboradores en 1997, se observó el reconocimiento por parte de sueros de pacientes con infección primaria y secundaria a cinco péptidos de la proteína no estructural NS1 y un péptido de NS3, lo que sugiere que estos epítopos se encuentran expuestos durante la infección natural por dengue (53).

La NS3 es la segunda proteína en tamaño, con un peso molecular entre 68 y $70 \mathrm{kD}$, asociada a la membrana. Es altamente conservada en los flavivirus y se piensa que sea un componente de la maquinaria enzimática de la replicación del ARN viral. La comparación de sus secuencias nucleotídicas y los análisis bioquímicos sugieren que es trifuncional, conteniendo actividad de proteasa (contra la poliproteína), de helicasa y de ARN trifosfatasa trifosfato (formación de la estructura 5' cap) (38). Su extremo $\mathrm{N}$ terminal contiene el dominio catalítico de la proteasa NS2b-NS3, parecido a la serina-proteasa de las subfamilias de las tripsinas. Esta triada catalítica está conformada por His 51, Asp 75 y Ser 135. Se cree que la actividad proteolítica de esta enzima sea la responsable del corte de NS2b, NS3, NS4a, NS5 y del extremo carboxilo de la proteína $\mathrm{C}(54,55)$. En esta proteína existen regiones homólogas con la familia de las helicasas, así como un fragmento $\mathrm{C}$ terminal de $50 \mathrm{kD}$ derivado de la proteolisis, que tiene actividad ARN trifosfatasa y está involucrado en la formación de la estructura de la caperuza del extremo $5^{\prime}$ del genoma del flavivirus (56).

Las regiones hidrofóbicas menos conservadas de la poliproteína son procesadas en al menos 4 proteínas no estructurales adicionales (NS2a, NS2b, NS4a y NS4b). Poco se conoce de las funciones de estas en el ciclo de vida de los flavivirus (38). Sin embargo, se conoce que la NS2b, de $27 \mathrm{kD}$, junto con la NS3 forma un complejo esencial para el procesamiento de todos los sitios de corte de las proteínas no estructurales y las estructurales $(38,57)$.

La última proteína codificada es la NS5, que es la más grande de 103 a $104 \mathrm{kD}$, bifuncional y una de las más conservadas en los flavivirus. Es una proteína básica y se cree que funciona como una ARN polimerasa dependiente del ARN, aunque no se ha verificado directamente. Esto se basa en la presencia de una región altamente conservada (YF NS5 666668) característica de este tipo de enzima presente en los virus ARN con cadena positiva. Se ha sugerido que puede estar involucrada en la metilación de la estructura de la caperuza $5^{\prime}$ terminal (38).

En los últimos años, se han realizado estudios en pacientes con infección primaria y secundaria por dengue para definir las proteínas involucradas en el reconocimiento por anticuerpos (58). En pacientes con infección primaria en fase de convalecencia y bajos 


\section{Acosta-Bas, I Gómez-Cordero.}

títulos de anticuerpos IgG a la proteína E, existe reconocimiento a NS3 y NS5. En pacientes con infección secundaria, en fase de aguda, se encontraron anticuerpos $\mathrm{IgG}$ contra la proteína $\mathrm{E}$ y en fase convaleciente, altos títulos de anticuerpos IgG a otras proteínas, incluidas la NS1, NS3, NS5 y C.

Los anticuerpos contra las proteínas E, NS3 y NS5 pueden ser detectados a los 5 días de la aparición de los síntomas. Estas tres proteínas y los anticuerpos contra ellas pueden estar involucradas en los mecanismos inmunopatogénicos de esta enfermedad. La confirmación de esta enfermedad podría basarse en la identificación de anticuerpos contra estas proteínas no estructurales.

En la mayoría de los casos con infección secundaria, en fase convaleciente, se observan anticuerpos contra las proteínas no estructurales NS3 y NS5, y en cerca del $40 \%$ contra la proteína NS1.

\section{Determinantes antigénicos.}

Recientemente se ha propuesto un modelo basado en la cristalización de la proteína $\mathrm{E}$ del virus de la encefalitis transmitida por garrapata, según el cual, esta proteína presenta una estructura inusual cuando se compara con otras proteínas. Uno de los aspectos más relevante, es que este modelo permite esclarecer la presentación de diversos epítopos con importantes funciones biológicas. De igual forma ha permitido establecer las bases estructurales para explicar el cambio que sufre esta proteína de una estructura dimérica a una estructura trimérica, así como la importancia de este fenómeno para el reconocimiento de la proteína por diversos anticuerpos frente a variaciones de $\mathrm{pH}$ (59).

Estudios funcionales de la proteína de la envoltura, han permitido caracterizar los dominios responsables de la neutralización, de la hemaglutinación (HA) de los glóbulos de gansos y de la fusión e interacción del virus con los receptores celulares específicos presentes en la superficie de las células $(60,61)$.

Por otra parte, usando anticuerpos monoclonales, se han realizado mapas de epítopos antigénicos asociados con la neutralización. En ellos se pueden observar de 3 a 4 sitios antigénicos mayores. Sin embargo, los epítopos inmunodeterminantes en ratones pueden no serlo en humanos y viceversa (39).

En la actualidad se realizan esfuerzos significativos para determinar el tamaño de las cadenas, así como los cambios conformacionales a pH ácido. Además, para localizar los epítopos neutralizantes en las regiones específicas de la proteína E, mediante el uso de péptidos sintéticos, la expresión de las proteínas en bacteria y levaduras o por neutralización con anticuerpos monoclonales, de variantes que escapan a los anticuerpos neutralizantes tradicionales (34).

Se han podido definir grupos de epítopos empleando anticuerpos monoclonales:

a) Epítopos conformacionales, ligados a la configuración espacial de las moléculas que se juntan topológicamente a partir de los residuos elongados en la secuencia. Ellos son en sí de la región A y de la $\mathrm{B}$, sensibles a la reducción de los puentes disulfuro y a la desnaturalización de la proteína. $(39,62,63)$.

b) Epítopos lineares o secuenciales, independientes de la estructura tridimensional de las proteínas que presentan una especificidad de complejo reconocimiento de la secuencia en el extremo Nterminal (a.a 37-52 y a.a 73-93) y en el lazo del dominio B (a.a. 312-320) del virus del Dengue (62, 63).

Estos estudios están en desarrollo y es prematuro dar una conclusión completa referente a estos métodos modernos para el análisis de determinantes antigénicos e inmunogénicos de la proteína $\mathrm{E}$.

Según estos resultados, aparentemente, la proteína de la envoltura no presenta secuencias peptídicas lineares correspondientes a epítopos susceptibles de inducir anticuerpos neutralizantes protectores, pero sí varios epítopos T, compuestos, por definición, de secuencias lineares. Ellas están presentes en la proteína $\mathrm{E}$ de cualquier flavivirus y en particular en el Dengue 2 (Denv-2). Estos epítopos contenidos en las secuencias B y C, estimulan una respuesta proliferativa de células $\mathrm{T}$ auxiliadoras inducidas por la infección viral en ratones. Algunos de estos epítopos pueden ser reconocidos por varios haplotipos de ratón y podrían ser estudiados para el humano (64). 


\section{Biología y diagnóstico del dengue.}

En cuanto a la respuesta de anticuerpos a las proteínas estructurales, en el trabajo publicado por V. Churboonchart, en 1991, se pudo constatar que en la infección primaria la mayoría de los sueros reconocen la proteína E. En las infecciones secundarias, en fase convaleciente es posible detectar, en la mayoría de los sueros, anticuerpos contra las proteínas estructurales E y C. En cerca del $20 \%$ contra la proteína prM y solamente en el $2 \%$ contra la proteína $\mathrm{M}(58)$.

\section{Serotipos del virus $(13,14)$.}

El dengue es un arbovirosis ocasionado por cualquiera de los cuatro serotipos diferentes del virus (Denv-1, Denv-2, Denv-3 y Denv-4), estrechamente relacionados, pero serológicamente distintos. Dentro de cada serotipo hay varias cepas y genotipos, que probablemente son más o menos virulentas, pero los factores de virulencia no son totalmente conocidos. Por ejemplo el Denv-2 presenta 2 genotipos (el del sudeste asiático y el americano) el primero asociado al dengue hemorrágico y el segundo al dengue benigno (10).

Cada serotipo crea inmunidad específica a largo plazo contra el mismo serotipo (homólogo), de por vida.Y aún cuando son antigénicamente similares, la infección por un serotipo, no produce inmunidad contra los otros serotipos, sólo produce inmunidad parcial, o sea, no proveen inmunidad cruzada $(6,12$, 29, 30, 35, 37).

Los cuatro serotipos son capaces de producir infección asintomática, enfermedad febril y cuadros graves que pueden conducir hasta la muerte, dada la variación genética en cada uno de los cuatro serotipos. Algunas variantes genéticas parecen ser más virulentas o tener mayor potencial epidémico $(17,19,30-32$, $35)$.

Los cuatro serotipos del virus del dengue son de amplia distribución en diversos países: Filipinas, sudeste Asiático, India, islas del Pacífico, Nueva Guinea, Australia septentrional, Grecia, Malasia y Tailandia. En América, se describe desde el Sur de EE.UU hasta la Argentina, habiéndose descrito en forma epidémica en Cuba, Centroamérica, Trinidad y
Colombia $(11,22,23,30,33,66-69)$.

\section{Distribución de los serotipos por países.}

Denv-1: Caribe, Centro América, México, sur de EUA, Colombia, Nigeria, Senegal, India, Bangladesh, Filipinas y Australia.

Denv-2: Caribe, México, Venezuela, Colombia, Senegal, Kenya, Nigeria, India, Bangladesh y Filipinas.

Denv-3: India, Bangladesh, Filipinas, Pakistán, Sri Lanka, México. Centro América y Australia.

Denv-4: SE de Asia, Sri Lanka, India, China, Centro América, Surinam, México, Colombia.

En un estudio realizado en Bangkok el Denv-3 fue el serotipo más frecuentemente aislado en infección primaria (49\%), Denv-2 en secundaria y en fiebre hemorrágica (37\% y 35\%, respectivamente). El serotipo predominante varió por años: en 1990-92 fue Denv-1; de 1973-86 y 1988-89, Denv-2; en 1987 y 1995-99, Denv-3 y en 1993-94, Denv-4 (70).

La circulación de los serotipos ha ido de ninguno o uno a múltiple, en la mayoría de los países (8), y en varios se ha observado la circulación simultánea de los serotipos 1, 2 y 4 durante varios años lo que pone a estos en grave riesgo de DH epidémico (5).

\section{Clasificación de la fiebre por dengue.}

La OMS distingue 4 grados de severidad en la enfermedad (5,10-12,71-73).

Grado I: fiebre, síntomas constitucionales no específicos, la prueba del torniquete es positiva. Corresponde a la forma benigna (Fiebre de dengue).

Grado II: Grado I + sangrando espontáneo (la piel, las encías, el tracto digestivo). También corresponde a la forma benigna.

Grado III: Grado II + fallo circulatorio y agitación. Corresponde a la forma severa (puede expresarse como "Dengue Hemorrágico" (DHF) o como "Síndrome de choque Hipovolémico por Dengue (SCD) que puede ser mortal.

Grado IV: Grado III + el choque profundo, pulso y tensión arterial no detectables. También corresponde a la forma severa.

\section{Formas clínicas del dengue.}

El dengue presenta un amplio espectro clínico, 


\section{Acosta-Bas, I Gómez-Cordero.}

las diferentes formas clínicas de este arboviros han sido comparadas por Guzmán y Kouri con un "iceberg" en cuya base se encuentran las infecciones asintomáticas, en el nivel intermedio la forma benigna (DC, 95\% de los casos) y en los superiores, la forma hemorrágica (DHF) y el síndrome de choque hipovolémico por dengue (SCD), que constituyen el $5 \%$ de los casos (figura 3$)(6,10,74)$.

Está reportado que en los casos de FHD el ataque es abrupto en todos los pacientes. El 97\% presenta dolor de cabeza intenso, el $90 \%$ mialgia, el $40 \%$ salpullido superficial, el 29\% vómitos y el $9 \%$ artralgia en la rodilla y junturas de la cadera. También anuria, linfoadenopatía, hepatomegalia, esplenomegalia (10$12,17,20,22,25,31,32,66,67,73,75)$.

DESARROLLO DE LA ENFERMEDAD

ASINTOMÁTICO SINTOMÁTICO

\begin{tabular}{|c|c|}
\hline DENGUE CLÁSICO & DENGUE HEMORRÁGICO \\
\hline SIN CHOQUE & CON CHOQUE (SCD) \\
\hline
\end{tabular}

Figura 3.- Formas clínicas del Dengue.

En el rango de la forma benigna, se observa principalmente en menores de 15 años, casos de infección asintomática o con sintomatología leve (fiebre leve o moderada, presencia o no de rash cutáneo). Los factores de edad, sexo y raza, merecen un análisis cuidadoso y profundizar en los estudios epidemiológicos y genéticos. Hay quienes afirman que la predisposición a la forma severa del dengue, desciende de manera significativa pasados los 12 años de edad y otros que el incremento de la edad favorece el riesgo de desarrollar las formas severas de la arbovirosis; en cuanto al sexo, las mujeres enfermarían con más frecuencia que los hombres y en la raza, la caucásica se afectarían más a menudo que los de raza negra (10-12,17,20,22,25,31,32,66,67,73,75).

Fiebre por dengue. Se presenta un cuadro clínico caracterizado por aparición repentina de fiebre así como la presencia de signos y síntomas no específicos, incluyendo dolor frontal de cabeza, retro- orbital, articular y muscular, náuseas, vómitos y debilidad, erupción en la piel, molestia a la luz, enrojecimiento de la faringe, conjuntivitis, dolor abdominal leve, náuseas, vómito, diarrea, alteraciones del gusto, prurito generalizado, insomnio, temor, depresión, así como bradicardia relativa y adenopatías (10-12,17,20,22,25,31,32,66,67,73,75).

Dengue hemorrágico (FHD). Durante la fase aguda es difícil diferenciarlo de la fiebre por dengue, pero en la fase crítica del FHD, se manifiestan síntomas de falla circulatoria o se pueden presentar manifestaciones hemorrágicas cuando decrece la temperatura hasta un estado normal. Los síntomas incluyen: hemorragias epiteliales, de mucosas y de órganos internos (petequias, púrpura, esquimosis, hematuria, epistáxis, sangrado de encías, sangrado intestinal y gástrico, prueba del torniquete, positiva a causa de las micro-hemorragias de los capilares de la piel), ascitis, derrame pleural, hepatomegalia y un aumento en la permabilidad vascular, que puede ocasionar choque hipovolémico debido a la "fuga" de plasma hacia el espacio extravascular e intersticial. El período de shock dura sólo uno o dos días y la mayoría de pacientes responde rápidamente a una vigilancia estrecha con oxigenoterapia, rehidratación y otras medidas (10-12,17,20,22,25,31,32,66,67,73,75).

En la forma benigna de esta infección, hay una respuesta inmunitaria con predominancia de la subpoblación linfocitaria TH1 y que en cambio en su forma severa, es la actividad de tipo TH2 la que influencia el desarrollo de la enfermedad (10-12, 17, 20, 22, 25, $31,32,66,67,73,75)$.

Síndrome de choque por dengue (SCD). Es la forma más grave de dengue, necesariamente requiere tratamiento hospitalario, ya que el sistema circulatorio del paciente se ve muy comprometido, aparecen signos de insuficiencia circulatoria, la piel se torna fría, a menudo hay cianosis, pulso débil y rápido, el paciente puede presentar letargo, inquietud y luego entra en la etapa de choque que se caracteriza por pulso acelerado y débil, reducción de la presión del pulso (20 mmHg o 2,7 kPa o inferior) o hipotensión marcada con piel fría, húmeda y agitación (10$12,17,20,22,25,31,32,66,67,73,75)$. 


\section{Biología y diagnóstico del dengue.}

Estos pacientes están en peligro de muerte si no se les administra enseguida el tratamiento adecuado. La mayoría se mantienen conscientes casi hasta la etapa final.

Esta etapa es corta, el paciente puede morir de 12 a 24 h o recuperarse con rapidez después del tratamiento; no corregido puede llevar a la acidosis metabólica, hemorragia grave del aparato digestivo o cualquier otro órgano con un pronóstico desfavorable. Puede aparecer también encefalopatía por alteraciones metabólicas y electrolíticas. La convalescencia en el FHD con o sin choque suele ser corta, aún en casos de choque profundo. Una vez corregido éste, los pacientes se recuperan entre 48 a $72 \mathrm{~h}(4,10-$ $12,17,20,22,25,31,32,66,67,73,75)$.

Dengue hemorrágico sin choque. Las manifestaciones clínicas son semejantes a las del dengue clásico, es decir, fiebre alta, vómitos, cefalea, artralgias, mialgias, anorexia, etc. La epigastralgia, la sensibilidad en el reborde costal derecho y el dolor abdominal son comunes. La temperatura es alta del $2^{\circ}$ al $7^{\circ}$ día y posteriormente baja a nivel normal o subnormal. En ocasiones sube a $40^{\circ} \mathrm{C}$ o más y puede acompañarse de convulsiones febriles. La manifestación hemorrágica más común es una prueba del torniquete positiva. En muchos casos se encuentran hemorragias en sitios de venipunción. En la etapa inicial podemos ver petequias finas diseminadas por las extremidades, axila, cara y paladar blando. Puede verse erupción maculopapular al principio y al final de la enfermedad. Las epistaxis y la hemorragia gingival son poco frecuentes. Puede existir hepatomegalia de 2 a $4 \mathrm{~cm}$, dolorosa a la palpación (10$12,17,20,22,25,31,32,66,67,73,75)$.

\section{Inmunopatogenia.}

El mecanismo inmunopatológico, que se desarrolla ante la infección de los serotipos de dengue; no se conoce con exactitud pero se han desarrollado modelos hipotéticos para tratar de explicar por qué un paciente puede desarrollar FDH o quedarse en la fiebre por dengue (FD). Las dos teorías más aceptadas son $(11,76)$ :

$1^{\text {ra: }}$ si un caso ha sido infectado en una primera infección por un serotipo, especialmente el Dengue 1 , queda protegido contra ese serotipo, pero no contra los otros serotipos y, al contrario, en una infección secundaria o terciaria, los anticuerpos de la primera infección, facilitan la ayuda de estos segundos virus infectantes hacia los monocitos, donde se multiplicarán en gran cantidad, empobreciendo la membrana celular, lo que ocasiona salida de sustancias vasoactivas como: bradiquina, histamina, sustancias activadoras del complemento, citoquinas y otras, que llevan al aumento de la fragilidad capilar lo que ocasiona salida del plasma del espacio intravascular al extravascular, produciéndose los derrames pleurales, abdominales, articulares y en cualquier otro espacio del organismo. Esto lleva a la deplesión del volumen sanguíneo y, como consecuencia, se desarrolla el SCD. También se activan las sustancias que estimulan la aparición de la coagulación intravascular diseminada (CID) lo que agrava el síndrome de choque.

Se incluyen, los menores de 1 año de edad con infección primaria nacidos de una madre portadora con experiencia inmunológica con dengue, los cuales portan anticuerpos transferidos por vía transplacentaria (5).

$2^{\text {da: }}$ hay serotipos de virus muy agresivos cuya virulencia se potencia en los pases sucesivos del mosquito al hombre y del hombre al mosquito, ocasionando formas severas de FHD y de SCD que pueden llevar a la muerte en la primera infección que sufra una persona.

\section{Replicación-transmisión.}

El ciclo de transmisión del virus del dengue por el mosquito Aedes aegypti comienza con una persona infectada con el dengue, que tendrá el virus circulando en la sangre (viremia que dura aproximadamente cinco días) (72).

El virus es inoculado en los seres humanos con la saliva del Aedes aegypti hembra, este se localiza y se replica en diversos órganos diana, por ejemplo, nódulos linfáticos locales e hígado. Posteriormente se libera y se difunde por la sangre para infectar los leucocitos y otros tejidos linfáticos, de ahí es liberado y circula en la sangre (72).

El mosquito ingiere sangre que contiene el virus, 


\section{Acosta-Bas, I Gómez-Cordero.}

que se replica en su zona embrionaria del tubo digestivo, los ovarios, el tejido nervioso y el cuerpo graso. Se difunde luego en la cavidad corporal y posteriormente infecta las glándulas salivales, donde se replica. Cuando el mosquito pica a otro ser humano, el ciclo continúa (72).

\section{Número de casos de Dengue.}

En América Latina, la Organización Panamericana de la Salud (OPS) registró en el 2001 alrededor de 610,625 casos de dengue en 20 territorios nacionales. Los países con mayor número de infecciones fueron Brasil (390,701casos), Venezuela con 83,180 (6,541 hemorrágico), Colombia con 55,437 (6,563 hemorrágicos) y Perú con 23,304 (10).

En el sureste de Asia, en el 2001, ocurrieron 119,707 casos de Dengue/Dengue hemorrágico y 452 fallecimientos por esta causa (77).

En el 2001 también, se observó un aumento progresivo del número de casos de dengue hemorrágico particularmente en países de América central (El Salvador, 55 casos; Nicaragua 458, Honduras 431, México 191, Perú) (10).

Según reporte de la Organización Panamericana de la Salud, hasta el 3 de febrero del 2004 el número de casos de Dengue en las Américas es como se refleja en el cuadro 1 (68):

\section{Cuadro 1}

Número de casos de Dengue en las Américas

(3 febrero 2004).

\begin{tabular}{lccc}
\hline Subregión & Dengue & DHF & Muertes \\
\hline Andina & 93,240 & 6790 & 27 \\
América Central & 46,305 & 758 & 26 \\
Cono sur & 324,738 & 618 & 33 \\
Caribe & 8,647 & 287 & 75 \\
\hline
\end{tabular}

Factores de riesgo en la aparición, distribución y transmisión del dengue.

Los factores de riesgo en la aparición, distribución y determinantes de la transmisión del Dengue se dividen en (5):

\section{Revista Biomédica}

Macrofactores: son los factores de riesgo ambientales y sociales, que a su vez pueden dividirse en:

Ambientales: una latitud de $35^{\circ} \mathrm{N}$ a $35^{\circ} \mathrm{S}$, una altitud de $2,200 \mathrm{~m}$, una temperatura entre $15-40^{\circ} \mathrm{C}$ y la humedad relativa de moderada a alta (33).

Sociales: la densidad de la población de moderada a alta; viviendas con tejidos de alambre inadecuados, desagües obstruidos con desechos; agua almacenada por más de 7 días, ausencia de abastecimiento de agua corriente individual, disponibilidad intermitente y uso de depósitos destapados. También incluye la recolección de desechos sólidos, el estado socioeconómico, los períodos inactivos en la casa durante el día y las creencias y conocimientos sobre el dengue.

Microfactores: son aquellos factores de riesgo del huésped, el agente y el vector.

Factores del huésped: incluye el sexo, la edad, el grado de inmunidad, las condiciones de salud específicas y la ocupación.

Factores del agente: las cepas y nivel de viremia.

Factores del vector: la abundancia y focos de proliferación del mosquito; la densidad y edad de las hembras, la frecuencia de alimentación, preferencia de huéspedes, disponibilidad de huéspedes y susceptibilidad innata a la infección.

\section{Diagnóstico viral (78).}

El diagnóstico viral en el laboratorio incluye:

Técnicas directas para la demostración viral.

- Las que visualizan la partícula viral o su efecto celular específico como las tinciones para microscopía de luz, la microscopía electrónica y el cultivo o aislamiento viral (los más empleados son cultivos primarios, cepas de células diploides y líneas celulares).

- Las pruebas para demostración de antígenos virales, que permiten descubrir y caracterizar un virus en cultivo celular cuando todavía no se produce el efecto citopático, o éste no es evidente o en los casos en que el virus se debe reconocer por otras propiedades o características en cultivo: la hemadsorción, la inmunofluorescencia directa (IFA), 


\section{Biología y diagnóstico del dengue.}

radioinmunoensayo (RIA) o inmunoensayo ligado a enzimas (ELISA o EIA) y las pruebas de látex.

- Las que evidencian o descubren el material genético específico viral conservado y replicable ya sea que se encuentre en un fluido, en una célula o tejido, ya sea activo o latente: ensayos de amplificación genética (reacción en cadena de la polimerasa, PCR; Reacción en cadena de la ligasa o LCR, Sistema QB replicasa, ADN ramificado (branched) o bADN) e hibridización (sondas).

Técnicas indirectas para el descubrimiento viral.

Estas son las técnicas serológicas tradicionales para descubrir anticuerpos contra determinado agente viral, teniendo en cuenta que la exposición al agente produce una respuesta por parte del sistema inmune que genera la producción de anticuerpos específicos. Estos ensayos se pueden clasificar en tres grupos con base en la cuantificación de la reacción antígenoanticuerpo.

a. Los que dependen de la capacidad del anticuerpo que se une al antígeno para ejercer alguna función no relacionada con el virus, por ejemplo: la fijación del complemento (FC), hemaglutinación indirecta (HI), aglutinación por látex.

b. Los que miden la capacidad de los anticuerpos para bloquear la función viral específica como la neutralización, la inhibición de la hemaglutinación(IH), la inhibición de la neuraminidasa (que mide la capacidad de los anticuerpos para bloquear la infectividad viral), la hemaglutinación viral y la actividad de neuraminidasa.

c. Los que miden directamente la interacción antígeno-anticuerpo como por ejemplo: la IFA indirecta, el RIA, ELISA, Inmunoblot y Western blot. Diagnóstico del Dengue.

El diagnóstico del laboratorio es esencial para la confirmación del dengue (6), este incluye técnicas de aislamiento e identificación del virus, de diagnóstico serológico y de biología molecular (detección del ARN del dengue) $(20,57,78)$.

La detección de antígenos virales en sueros virémicos es necesaria para las investigaciones clínicas y epidemiológicas y debe realizarse rápidamente para implantar tempranamente el tratamiento anti-choque a los enfermos y la detección precoz de un brote (57).

\section{Detección del antígeno.}

Por diferentes investigaciones se ha podido constatar, que la viremia ocurre en la etapa temprana del período febril del dengue y su eliminación es cuando disminuye la fiebre y aumentan los niveles de anticuerpos. Los primeros en demostrar esto fueron Ashbur y Craig en una investigación en Manila en 1906. Por consiguiente, al aplicar las técnicas de aislamiento viral en muestras tomadas en el primer día de la aparición de los síntomas por lo general son positivas, esto se ha detectado en el $73 \%$ de los casos (7981).

\section{Aislamiento e identificación del virus $(82,83)$.}

Para la técnica del aislamiento del virus, se debe obtener una muestra de suero tan pronto sea posible o dentro de 5 días después de la fecha del comienzo de síntomas (11), ya que se ha podido constatar que el período virémico se encuentra entre los días 4 y 5 después del comienzo de los síntomas (83).

Es una técnica útil y sensible para la confirmación de la infección por el virus de dengue, sobre todo si se toma la muestra antes de que desaparezca la fiebre $(82,84,85)$.

Aunque el dengue es una de las principales enfermedades virales en el hombre, sus cuatro serotipos se consideran entre los que mayores dificultades tienen para su aislamiento y multiplicación en el laboratorio (86). Entre estas técnicas se encuentran:

Aislamiento viral en ratones: la inoculación intracerebral de la muestra en ratones recién nacidos (1 ó 2 días) es el método tradicional y a su vez el menos sensible, para el aislamiento del virus $(82,83)$.

Aislamiento en células de cultivos y en mosquitos: las técnicas de cultivo de tejidos en aislamiento de los virus del dengue aumentó considerablemente su eficacia, aunque todavía no se ha encontrado ninguna línea celular de mamíferos o de mosquitos en donde todas las cepas del virus dengue produzca un efecto citopatogénico $(82,83)$.

Varias líneas celulares de mamíferos se han usado con distintos grados de sensibilidad, para el aislamiento 


\section{Acosta-Bas, I Gómez-Cordero.}

de estos virus (LLCMK 2; BHK 21). Las células de mosquitos se han utilizado en forma creciente ya que resultan mejores para el aislamiento pues son más sensibles, fáciles de multiplicar y mantener a temperatura ambiente, se mantiene hasta 14 días sin necesidad de cambiarles el medio de cultivo y pueden llevarse al terreno y ser inoculadas directamente con suero de pacientes. Las líneas celulares de mosquitos que han mostrado una mejor sensibilidad para el aislamiento (AP 61; C636; Tra284; CLA-1) (82, 83). La inoculación de mosquitos adultos, es el método desde el punto de vista técnico, que resulta más sensible para el aislamiento viral. El aedes albopictus y el toxorinchites splendens son los utilizados.

A pesar de esta ventaja el método de elección analizando la sensibilidad del sistema y la factibilidad de su realización es el aislamiento en línea celular C636 que se logra en un porcentaje relativamente alto y al mismo tiempo es sencillo en su ejecución pues la inoculación de mosquitos resulta engorroso ya que requiere habilidades especialidades y el tener las colonias en insectarios, que son instalaciones relativamente costosas y no frecuentes en nuestra región $(82,83)$.

En aislamientos virales en muestras con infección primaria el número de casos positivos oscila entre el 51 y el $100 \%$, demostrándose, además, que es en estos pacientes donde se encuentran los mayores títulos de antígeno (84).

Aislamiento e identificación viral (Tomado del Manual de Procedimiento del IPK. Cuba y Método que se realiza en CNDR- MINSA. Nicaragua)

Este procedimiento consta de los siguientes pasos (82,83,87):

I. Multiplicación de células C636

II. Congelación de células C636

HHH. Descongelación

IV. Aislamiento viral

V. Identificación viral por inmunofluorescencia indirecta (IFI).

Las células fluorescentes se observarán cuando haya una reacción con el monoclonar especifico. Un aislamiento positivo confirma un caso de dengue.
Lo ideal en un procedimiento diagnóstico es la detección de antígenos virales en muestras clínicas, seguido por su identificación. El aislamiento y tipificación de virus permite la detección e identificación específica del dengue, pero su sensibilidad depende mucho de una adecuada recolección y conservación de la muestra, y requiere de 5 a 10 días para dar resultados apareados (87, 88).

El método más sensible, rápido y económico de identificación del virus es mediante la inmunofluorescencia indirecta, utilizando anticuerpos monoclonales específicos contra los cuatro serotipos del virus (86).

\section{Diagnóstico serológico $(82,83)$.}

Para el diagnóstico serológico, se requiere una muestra de suero en la etapa convaleciente obtenida al menos 6 días después de la fecha de comienzo del primer síntoma (12).

Los estudios sobre la repuesta de anticuerpos al dengue comenzaron en 1930 con el desarrollo de una técnica de fijación del complemento. En la década de los 60 empezó a utilizarse una técnica de inhibición de la hemaglutinación con el fin de detectar anticuerpos totales contra los cuatro serotipos del dengue y clasificar las infecciones en primarias o secundarias (89-91).

En estudios recientes en infecciones primarias sobre la cinética de la respuesta de anticuerpos, se demostró el incremento de los de tipo IgM en prácticamente todos los pacientes, a los dos días de la disminución de la fiebre; con un pico en la respuesta aproximadamente a las dos semanas. En infecciones no primarias, la respuesta de anticuerpos IgM es variable, en algunas ocasiones está ausente o es muy baja, pero existe un marcado incremento de los de tipo IgG (figura 4) $(92,93)$.

Tan pronto como surgió el método ELISA fue evaluado para los flavivirus. Las desventajas de este método son su baja sensibilidad, pues requiere de títulos muy altos de virus para obtener una correcta identificación y que no reaccionen con cepas de cierta distribución geográfica. En el caso de los virus del

\section{Revista Biomédica}




\section{Biología y diagnóstico del dengue.}

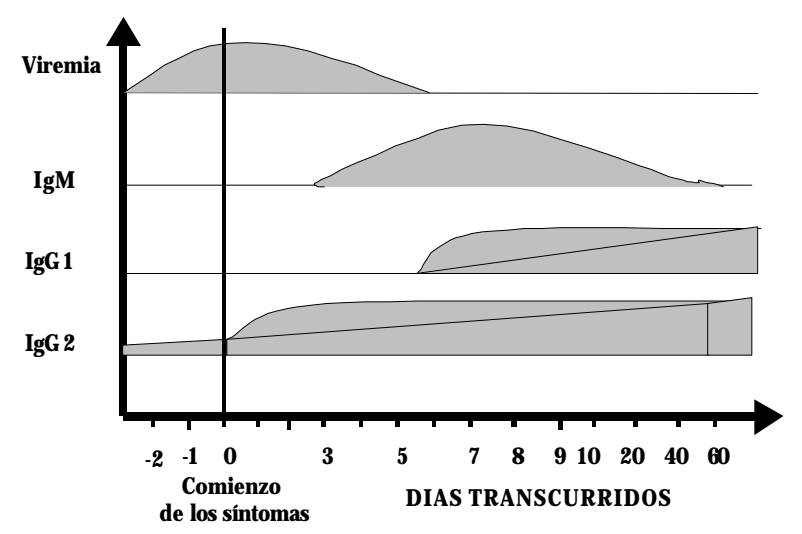

Figura 4.- Cinética de la respuesta inmune durante la infección por dengue.

dengue esta sensibilidad fue extremadamente baja.

Estos virus propagados en células de mosquito pueden ser identificados fácilmente utilizando anticuerpos monoclonales tipo específico, pero estos métodos son muy laboriosos.

Los ensayos ELISA para el diagnóstico incluyen los típicos ensayos de captura en fase sólida para la detección de anticuerpos IgM e IgG y la detección de anticuerpos IgE e IgA en suero, plasma o saliva $(94,95)$.

Inmunoensayo enzimático (ELISA) de captura para IgM anti-dengue. Método de elección por su economía, sencillez y relativa rapidez. Es de gran utilidad para el trabajo durante epidemias y constituye el sistema de elección para la vigilancia seroepidemiológica ya que tiene una elevada sensibilidad y especificidad, sin embargo, no permite identificar los serotipos circulantes $(12,82,83,86,87)$. Permite un diagnóstico rápido empleando una sola muestra colectada en fase aguda, el diagnóstico temprano de esta enfermedad se puede mejorar, si se colecta una segunda muestra alrededor del séptimo día de iniciados los síntomas $(91,94)$.

Los resultados de esta técnica deben interpretarse con cuidado, porque dependen en gran medida del momento en que se tome la muestra y del tipo infección (primaria o secundaria) que presente la persona afectada (87).

Los anticuerpos IgM se desarrollan rápidamente durante la infección (la positividad a IgM se ha reportado en el $98 \%$ de las muestras con dengue en fase convaleciente) y son detectables a partir del quinto día del comienzo de los síntomas, durando en sangre hasta 3 meses aproximadamente por lo que, los sueros convalecientes deberán ser colectados antes de que la IgM alcance niveles no detectables (65-67). La detección de anticuerpos IgM anti-dengue indica una infección activa o reciente. $(4,12,82,83)$.

ELISA de captura de IgM. Las tiras son sensibilizadas con una inmunoglobulina de carnero anti IgM humana, que reaccionará con los anticuerpos de clase IgM presentes en la muestra del paciente. Al adicionar el antígeno del virus del dengue éste reaccionará con las inmunoglobulinas M capturadas si estas son específicas para el virus. Posteriormente se adiciona el conjugado, formado por inmuglobulinas anti virus dengue acopladas a la enzima peroxidasa del rábano, que reaccionará con el antígeno del virus. Cuando se adiciona el substrato este es degradado por la enzima peroxidasa traduciéndose en un cambio de color en la reacción en las muestras positivas (82, 83, 87).

El MAC-ELISA (captura de anticuerpos IgM anti-dengue) es el sistema propuesto por la OPS, por su elevada especificidad, sensibilidad y rapidez en su ejecución. Es una herramienta de gran valor para la vigilancia serológica de la fiebre del dengue y la FHD y es la prueba serológica seleccionada por la mayoría de los laboratorios (4).

Es apropiada para el análisis de sueros individuales colectados 5 o más días después del inicio de la enfermedad (MAC-ELISA) $(4,88)$.

Prueba de neutralización (Prueba de Neutralización por Reducción de placas): es costosa y laboriosa y pocos laboratorios la tienen normalizada en la región. Es muy útil para estudios retrospectivos y tratar de discernir los serotipos circulantes en una determinada región o grupo poblacional $(82,83,86$, 87).

Titulación del virus del dengue y neutralización por reducción de placas (Morens et al. Tomado del Manual de Procedimientos del IPK. Cuba).

Técnica de elevada especificidad, útil para la identificación viral y para la detección de anticuerpos contra el virus del dengue. Para esta prueba los virus 


\section{Acosta-Bas, I Gómez-Cordero.}

pueden ser aislados en cualquier sistema aunque en ocasiones es necesario realizar un pase por una línea de células de mamífero permisiva LLCMK2, y Vero y las de mosquitos.

La utilización de células BHK 21 en la técnica de placas (micrométodo) ha brindado resultados satisfactorios y rápidos (87).

Diagnóstico confirmatorio. Inhibición de la hemaglutinación y la fijación del complemento son específicas y sensibles pero más trabajosas y requieren de sueros pareados para la confirmación de los casos (86-88).

Hemaglutinación e inhibición de la hemaglutinación (Método de Clark y. Casals, Tomado del manual de procedimientos del IPK. Cuba) (87).

Algunos antígenos virales tienen capacidad para aglutinar eritrocitos de diversas especies, sin embargo la presencia de anticuerpos específicos en el suero del paciente evitan la aglutinación de los eritrocitos por tales antígenos; cuando esto ocurre se evidencia la presencia de anticuerpos (78).

El virus del dengue aglutina a eritrocitos de ganso y humanos del grupo O. Producto de la infección del virus se forman anticuerpos que se unen al virus e inhiben la hemaglutinación El título de un suero es considerado como la última dilución donde se inhibe la hemaglutinación (87).

Técnicas Moleculares (82, 83, 86).

El desarrollo de las técnicas de reacción en cadena de la polimerasa es claramente uno de los principales avances técnicos en el diagnóstico de las enfermedades virales. La habilidad para amplificar millones de veces una mínima cantidad de ácido nucleico provee a la técnica de un poder extraordinario.

Reacción en cadena de la polimerasa (PCR). Está utilizándose en forma creciente para el diagnóstico de los flavivirus y específicamente para el diagnóstico de los virus del dengue, Mediante esta técnica, el ARN viral es detectado en casi un $90 \%$. Es una técnica de diagnóstico muy útil debido a su sensibilidad, especificidad y detección rápida de cantidades mínimas de material genético viral en las muestras de pacientes. Además permite evidenciar una infección aunque el individuo se encuentre en ventana inmunológica, lo que permite disminuir la transmisión de estas infecciones (78).

Utilizando la PCR se han detectado directamente los virus del dengue en sueros de pacientes, en mosquitos infectados en sobrenadantes de cultivo infectados y en larvas de mosquitos. Además, permite el estudio de las características genéticas de las cepas circulantes y detectar el ácido nucleico viral en los tejidos de pacientes fallecidos por dengue.

La PCR potencializa la rapidez en el diagnóstico, pero requiere facilidades especiales y equipamientos muy caros.

\section{Transcripción reversa - reacción en cadena de la polimerasa (RT-PCR).}

Es un método "in vitro" que utiliza la síntesis enzimática para replicar selectivamente una región diana dentro de un ADN de doble cadena, de forma similar la amplificación de ARN puede ser hecha proporcionando una copia de ADN complementario $(\mathrm{ADNc})$ que haya sido previamente sintetizada por reverso transcriptasa. El principio fundamental es la amplificación de un fragmento específico de ADN, por medio de ciclos sucesivos de multiplicación exponencial, hasta llegar a obtener una cantidad adecuada del producto, el cual puede ser visualizado por electroforesis. Una sola molécula puede generar más de un millón de copias de sí misma luego de 30 ciclos de replicación exponencial $(230=1,073,741,842)(87)$.

Está comprendida de tres reacciones consecutivas, la desnaturalización, la hibridación y la polimerización elongación o extensión. Después de varios ciclos el producto predominante de la reacción será aquella pieza de ADN la cual está flanqueada por los cebadores e incluirá a los cebadores por sí mismos.

Versiones de RT-PCR:

$1^{\text {ra }}$ Se amplifica segmentos de la región de la cápside viral,

$2^{\text {da }}$ Es amplificada parte de la región no estructural del virus, NS3.

$3^{\text {ra }}$ El PCR nested o doble PCR o PCR anidada,

\section{Revista Biomédica}




\section{Biología y diagnóstico del dengue.}

en la que se hacen dos amplificaciones sucesivas a partir del producto inicial obtenido, en la primera se amplifica una región amplia del virus del dengue conservada en los 4 serotipos y en la segunda diferentes regiones específicas para cada serotipo (78).

Una muestra positiva es aquella donde se logra amplificar un fragmento de ADNc con el tamaño esperado. Un caso positivo por RT- PCR de dengue es un caso confirmado de dengue.

El RT-PCR es una prueba de diagnóstico útil y más sensible que el aislamiento del virus y titulación directa del virus para la confirmación de infección de virus de dengue en la infección secundaria, así como en la infección primaria, sobre todo cuando las muestras del plasma son obtenidos antes que la fiebre mengue (7).

La amplificación de los ensayos inmunoenzimáticos fluorigénicos ha sido descrita para la detección e identificación del dengue 3 en muestras de sueros. Este ensayo emplea placas recubiertas con anticuerpos monoclonales contra dengue 3 . Una vez incubada la muestra se adicionan anticuerpos monoclonales contra dengue biotinilados y seguidamente la beta galactosidasa-estreptavidina. Esta técnica da la posibilidad de combinar el efecto de amplificación de las interacciones biotina-estretavidina con una alta sensibilidad en la detección fluorigénica, gracias a la alta afinidad de la biotina por sus enlaces multivalentes a la estreptavidina unida a la beta galactosidasa. Después de la optimización de este procedimiento se redujeron las interacciones inespecíficas a las proteínas y se incrementaron los enlaces específicos por el antígeno (89).

El ensayo F-ELISA fue evaluado con 259 sueros para la confirmación del diagnóstico del dengue. La sensibilidad fue de $90 \%$, la especificidad de $99 \%$ y tuvo una coincidencia con el aislamiento viral del $98 \%$.

El ácido nucleico del virus de dengue puede detectarse con sondas específicas de ADNc o sondas sintéticas de oligonucleotidos $(42,58,62)$. Estas técnicas, usadas con sondas específicas de serotipo y topotipo, serán potencialmente útiles no sólo para la identificación sino también para hacer investigaciones epidemiológicas del movimiento de ciertos topotipos (58). La sensibilidad de esta técnica, en un estudio obtuvo un límite de $1 \mathrm{pg}$ de ARN de dengue 2 de 11-21 UFP y en otro se obtuvo sensibilidad de 2,75 log 10 DICT 50 con dengue 2 en mosquitos adultos $(62,90)$.

\section{Vigilancia epidemiológica proactiva.}

El dengue, por ser de rápida transmisión, requiere de un sistema de vigilancia epidemiológica proactiva capaz de detectar tempranamente la propagación viral y predecir las epidemias, a fin de orientar las medidas de control con antelación al momento de transmisión máxima $(87,88)$. La eficacia de este sistema depende de la capacidad de diagnóstico de laboratorio en la detección temprana de la circulación del virus (96) y requiere de técnicas de laboratorio rápidas y confiables.

Entre la técnica recomendadas están las pruebas serológicas de inhibición de la hemaglutinación (IHA) $(88,89)$, el ensayo inmunoenzimático de captura de IgM anti-dengue (MAC-ELISA) y la técnica virológica del aislamiento y la tipificación serológica del virus de dengue (AIV).

La implementación de la técnica RT-PCR, es una alternativa que ha sido utilizada exitosamente en sistemas de vigilancia proactiva de Centro y Sur América, debido a que permite detectar rápidamente, con buena sensibilidad y especificidad, mínimas cantidades de ARN del virus en todo tipo de muestras $(69,87,99-100)$, incluyendo las que contienen virus inactivados debido a un almacenaje inapropiado de la muestra, o a la formación de complejos virusanticuerpos neutralizantes $(98,101)$.

\section{Ejemplos de vigilancia epidemiológica proactiva.}

En Aragua State (Venezuela) usando las técnicas de aislamiento viral, inmunofluorescencia de serotipificación (VIIS), la RT-PCR, MAC-ELISA e inhibición de la hemaglutinación (HI), el 97,4\% de los sueros, resultaron positivos por lo menos una técnica. De ellos el $60,4 \%$ se clasificaron como casos confirmados (positivos virológicamente) y $39,6 \%$ como casos probables (negativos virológicamente/ 


\section{Acosta-Bas, I Gómez-Cordero.}

positivos serológicamente). Fueron detectados los serotipos Denv-1 (51.2\%), Denv-2 (37,9\%) y Denv$4(10,6 \%)$ en el $0,3 \%$ se detectó una infección dual de Denv-2 y Denv-4 (96).

Cuando se realizó un estudio comparativo de las cualidades de diagnóstico confirmatorio temprano del dengue de la técnicas RT-PCR, aislamiento viral en células C6/36 y serotipificación con anticuerpos monoclonales anti-dengue (AIV), ensayo inmunoenzimático de captura de IgM anti-dengue (MAC-ELISA) y la inhibición de la hemaglutinación (IHA), los resultados demostraron que la RT-PCR tuvo: a) mayores tasas de positividad que el AIV, el MAC-ELISA y la IHA; b) alta sensibilidad (100\%) y aceptable especificidad (73,5\%) respecto al AIV y c) buena eficacia y rapidez en obtener resultados en los cuatro días iniciales de la enfermedad. Cualidades que la convierten en una poderosa herramienta para la vigilancia proactiva del dengue (69).

\section{Ensayos desarrollados para la detección de} dengue.

Ensayo de microneutralization para la detección de anticuerpos anti-dengue. Para medir los antígenos virales se empleó un ELISA con anticuerpos antidengue de ratón y una enzima conjugada (anticuerpo anti-ratón). Los resultados de densidad óptica fueron procesados y graficados y fueron iguales a los de la prueba de neutralización de placa-reducción en las infecciones primarias por virus de dengue, pero la correlación fue pobre en las infecciones secundarias. La prueba ofrece las ventajas de facilidad de realización, facilidad en el cálculo de resultados, bajo costo, e incremento de la velocidad (102).

Ensayo inmunocromatográfico (IC) para la detección de anticuerpos IgM e IgG del virus del dengue. El 78,84\% de los pacientes (diagnosticados por Inhibición de la hemaglutinación) fueron positivos. Comparado la inhibición de hemagglutination, la prueba de IC mostró $79 \%$ sensibilidad y $95 \%$ especificidad y buena "agreement" $(\mathrm{k}=0,72)$; la eficacia fue de $86 \%$ (103).

ELISA, Dipstick ELISA para la detección de anticuerpos IgM e IgG en suero (104). La evaluación del Dipstick ELISA mostró una concordancia de $96 \%$ y $93 \%$ con respecto a un ensayo comercial Rapid PanBio Immunochromatographic test (IC test) en la detección de anticuerpos IgM e IgG respectivamente. La sensibilidad del Dipstick ELISA comparado con un ELISA de captura fue $83 \%$ y la especificidad de 98. Con respecto al IC test la sensibilidad para detectar anticuerpos IgM e IgG fue $84 \%$ y $94 \%$, respectivamente, y la especificidad fue $98 \%$ y $92 \%$, respectivamente.

ELISA NS1 serotipo-específico para diferenciar las infecciones primaria y secundaria del virus del dengue y los serotipos de la infección. El ensayo mostró buena correlación con un ensayo de neutralización (PRNT). Sugieren que este ensayo podría reemplazar a los PRNT en los estudios seroepidemiológicos para diferenciar la infección de dengue y encefalitis Japonesa y la serotipificación de dengue (105).

NASBA (isothermal nucleic acid sequencebased amplification), ensayo de amplificación viral del ARN optimizado, para la detección de los cuatro serotipos del dengue. El ensayo utiliza sílice para extraer el ácido nucleico viral que se amplificó sin el termociclador. El producto amplificado se descubrió por un método de sonda-hibridación. La detección es de 1 a 10 PFU/ml, la sensibilidad de $98.5 \%$ y la especificidad de $100 \%$ (106).

Restriction site-specific PCR (RSS-PCR), método de tipificación para los serotipos 1, 2, 3 y 4 del virus del dengue. Debido a su simplicidad es útil para una tipificación rápida y para estudios epidemiológicos en países endémicos (107).

\section{Ensayos comerciales disponibles.}

Dengue Duo Rapid Strip Test. PanBio, Brisbane, Australia: ensayo inmunocromatográfico que incorpora antígenos recombiantes. Es un ensayo de captura que se realiza en 15 min y detecta IgM e IgG. Las 4 proteínas recombinantes representan el $80 \%$ de la región n-terminal de las glicoproteínas de la envoltura viral de los subtipos 1, 2, 3, y 4. La sensibilidad y especificidad son de 90 y $86 \%$, respectivamente (108).

\section{Revista Biomédica}




\section{Biología y diagnóstico del dengue.}

PanBio Dengue Screening ELISA: es un ELISA de captura que IgM e IgG. Su sensibilidad en dengue primario y secundario fue de $95 \%$, la especificidad de $94 \%$ (109).

Pan Bio Dengue Duo ELISA: un ELISA de captura, específico para anticuerpos IgM e IgG producidos durante la infección por dengue. Posee una sensibilidad entre $99-100 \%$ y una especificidad de $92.8 \%(21,110)$.

MRL Diagnostics Dengue Fever Virus IgM Capture ELISA: ensayo de captura para IgM. Su sensibilidad es de $98 \%$ y $100 \%$ de especificidad (21, 111).

Pan Bio Rapid Immunochromatographic Test: Ensayo inmunocromatográfico, con una sensibilidad y especificidad de $100 \%$ en ambos casos (21).

Fueron evaluados los sueros 62 de pacientes con dengue (18 con tipo 2, 8 con dengue hemorrágico y 36 confirmados por serología) y 30 muestras negativas por cuatro ensayos comerciales para la detección de dengue $\operatorname{IgM}(9)$ :

ELISA IgM de captura (MRL Diagnostics, Cypress, Calif), que tuvo una sensibilidad de 98,4\%

ELISA IgM de captura (PanBio, Queensland, Australia), con $85,5 \%$ de sensibilidad

Dot ELISA dipstick assay (Integrated Diagnostics, Baltimore, Md.), con 96,8\%

Rapid immunochromatographic assay for dengue IgG and IgM (PanBio IC), con 83,9\%

Todos mostraron una especificidad del $100 \%$.

El dengue secundario se encontró en todos con el FDH y en el $83 \%$ de los restantes pacientes.

Con respecto a las pruebas inmunológicas, el desarrollo de un nuevo Kit de diagnóstico conocido como Dip-S-Ticks ha mejorado el sistema de diagnóstico para la detección de anticuerpos IgM frente al virus dengue (18).

\section{Tendencia actual en los métodos de diagnóstico del dengue.}

La tendencia actual en el diagnóstico del dengue se caracteriza por el desarrollo de ensayos que emplean como soporte sólido membranas de nitrocelulosa, ya sea en formato dot ELISA, inmunocromatográfico o dipstick ELISA $(94,112$, 113). En estos ensayos se buscan anticuerpos IgG e IgM en las muestras, con la finalidad de incrementar la rapidez del diagnóstico y la clasificación de la infección en primarias o secundarias. Además, de lograr la accesibilidad a zonas endémicas donde es difícil la realización del diagnóstico de esta entidad por la metodología tradicional.

Otra vertiente es el desarrollo de antígenos recombinantes y sintéticos con la finalidad de incrementar la especificidad del diagnóstico basado en la detección de anticuerpos. Se han evaluado proteínas recombinantes representativa de los cuatro serotipos del dengue obtenidas en $E$. coli en ensayos indirectos para la detección de anticuerpos IgG e IgM. Estos ensayos han sido comparados con los ensayos de captura que emplean antígeno natural, demostrando que los ensayos con antígeno recombinantes son igualmente sensibles en la detección de anticuerpos IgG e IgM. En relación con la especificidad del sistema, ocurre un mejoramiento sustancial de este parámetro ya que disminuye la interferencia de anticuerpos contra otros flavivirus y en específico los anticuerpos generados posterior a la vacunación contra estos virus (fiebre amarilla).

Las ventajas anteriormente mencionadas unido a la disminución del riesgo de manipulación de virus vivos, hacen que las proteínas recombinantes y sintéticas sean muy útiles en el desarrollo de nuevos ensayos para el diagnóstico del dengue.

Existen, sin embargo, algunas ambigüedades en la determinación de epítopos inmunogénicos. La utilización de fragmentos de proteínas funcionales o una proteína expresada en bacteria o de péptidos sintéticos forman parte de la naturaleza de estas ambiguiedades no obstante, siguen siendo una vertiente en la investigación con mayor perspectiva en el diseño de un candidato vacunal efectivo y el desarrollo de técnicas de diagnóstico con mayor especificidad y sensibilidad $(63,65,113-115)$.

\section{Tratamiento.}

Hasta el momento no existe tratamiento antiviral específico. El tratamiento de las formas 


\section{Acosta-Bas, I Gómez-Cordero.}

no complicadas, radica en indicar reposo, mantener hidratado al paciente (pueden utilizarse las sales de rehidratación oral) y administrar paracetamol, cuando el dengue adquiere la forma "rompe-hueso", es necesario en los primeros días, recurrir a la dipirona (5).

No existe ninguna vacuna disponible comercialmente y es improbable la disponibilidad de una vacuna efectiva contra los 4 serotipos de dengue en los próximos 10 años. Hace más de 20 años se trabaja en la obtención de una vacuna contra los 4 serotipos de dengue. La formulación más adelantada está constituida por virus atenuados contra los 4 serotipos del virus, aún en fase de estudio de campo. Esta preparación involucra todos los riesgos que representa una vacuna viva atenuada $(5,6)$.

El control del vector es en estos momentos la única alternativa para detener la propagación de la enfermedad (6).

\section{REFERENCIAS.}

1.- Wengler G, Wengler G. Flaviviridae. Arch Virol, 1991; 119 (suppl. 2): 223-233.

2.- Monath TP. Flaviviruses, En Fields BN, Knipe DM editors. Virology. New York: Raven Press, Ltd., 1990. p. 763-814.

3.- Dengue en Centroamérica. Las epidemias del 2000. [en línea] 2001 [fecha acceso 5 abril 2004] URL disponible en http://www.geosalud.com/enfermedades_infecciosas/ dengue_centroamerica.htm.

4.- Delgado I, Vázquez S, Bravo JR, Guzmán MG. Predicción del serotipo del virus del dengue mediante la respuesta de anticuerpos IgM. Rev Cubana Med Trop 2002; 54:113-117.

5.- Ortega LM. Dengue: un problema siempre emergente. Epidemiólogos Boletines IPK No 5 y 6 del 2002. [en línea] [fecha acceso 20 febrero 2004] URL disponible en http:// www.dhsint.com/epidemiologos/Buscador/abstract/106/ 106.asp.

6.- da Fonseca BA, Fonseca SN. Dengue virus infections. Curr Opin Pediatr, 2002; 14:67-71.

7.- Sangasang A, Wibulwattanakij S, Chanama S, Orapinpatipat A, Anuegoonpipat A, Anantapreecha S, et al. Evaluation of RT-PCR as a tool for diagnosis of secondary dengue virus infection. J Infect Dis 2003; 56:205-9.
8.- Isturiz RE, Gubler DJ, Brea del Castillo J. Dengue and dengue hemorrhagic fever in Latin America and the Caribbean. Infect Dis Clin North Am, 2000; 14:121-40.

9.- Branch SL, Levett PN. Evaluation of four methods for detection of immunoglobulin $\mathrm{M}$ antibodies to dengue virus. Clin Diagn Lab Immunol 1999; 6:555-7.

10.- Cruz A, Rolland L. El virus del dengue. Diagnóstico [en línea] 2002 [fecha de acceso 20 enero 2004] 41(4):165-172. URL disponible en http://www.fihu-diagnostico.org.pe/ revista/numeros/2002/julago02/165-172.html.

11.- Dengue: Manual Práctico. Grupo de consenso nacional para la prevención y control del dengue en Venezuela. [en línea] 2001 [fecha acceso 20 febrero 2004] URL disponible en http://www.reinaldogodoyeditor.com/subpaginas/ manualDengue.htm.

12.- Dengue y Dengue Hemorrágico Información para los Médicos. Centro para el Control y Prevención de las Enfermedades de los Estados Unidos. [en línea] 2000 [fecha acceso 20 febrero 2004] URL disponible en . http:// geosalud.com/enfermedades_infecciosas/dengue_ hemorragico.htm.

13.- Valdés L. Dengue. En: Enfermedades emergentes y reemergentes. C. Habana: Ministerio de Salud Pública; 1998. p. 178-95.

14.- Dengue. En: El control de las enfermedades transmisibles en el hombre. Informe oficial de la Asociación Estadounidense de Salud Pública. Ed. A. Benenson. Publicación Científica No. 538. OPS, Washington D.C; 1996. p. 82-6.

15.- Martínez E. Dengue y Dengue Hemorrágico. Ed. Universidad Nacional de Quilmes. 1998; 269 páginas.

16.- Expertos analizan la carga social, económica y epidemiológica del dengue. [en línea] 2002 [fecha acceso 15 enero 2004] URL disponible en www.paho.org.

17.- Kourí G. El dengue, situación actual en las Américas. Perspectivas para su control. Exposiciones de Taller Dengue en la UCV. Temas para el médico. [en línea] 2004 [fecha acceso 20 febrero 2004] URL disponible en http:// www.reinaldogodoyeditor.com/subpaginas/ tallerdengue.htm.

18.- Yábar C, Carrillo C, Nolasco O, García M, Montoya Y. Diagnóstico temprano del virus Dengue 1 usando RT-PCR y perspectivas para la caracterización molecular de cepas

\section{Revista Biomédica}




\section{Biología y diagnóstico del dengue.}

autóctonas. Rev Med Exp 1999; XV (1-2).

19.- Castleberry JS, Mahon CR. Dengue fever in the Western Hemisphere. Clin Lab Sci 2003; 16:34-8.

20.- Pancharoen C, Kulwichit W, Tantawichien T, Thisyakorn U, Thisyakorn C. Dengue infection: a global concern. J Med Assoc Thai 2002; 85 (Suppl 1):S25-33.

21.- Vajpayee M, Singh UB, Seth P, Broor S. Comparative evaluation of various commercial assays for diagnosis of dengue fever. J Trop Med Public Health, 2001; 32:472-5.

22.- Seijo A. Dengue grave: generalidades e inmunopatogenia. En: Dengue grave. Asociación de Alergia, Asma e Inmunología "Buenos Aires". Junio 1999.

23.- Dengue fever. CDC Dengue Fever Home Page, Division of vector-borne Infectious Diseases. [en línea] 2003 [fecha acceso 15 enero 2004] URL disponible en http:// www.cdc.gov/ncidod/dvbid/dengue/index.htm. 2003.

24.- Boletín especial sobre dengue. Oficina de Campo de la Organización Panamericana de la Salud, en El Paso Texas. [en línea] 1999 [fecha acceso 15 enero 2004] URL disponible en http://www.fep.paho.org/denguebul/spanish/ section2.htm.

25.- Ortega LM. Dengue: un problema siempre emergente. RESUMED 2001; 14(2):41-52 .

26.- OPS/OMS. Dengue y dengue hemorrágico en las Américas: guías para su prevención y control. Organización Panamericana de la Salud. Publicación Científica No. 548. Washington DC; 1995. p. 109.

27.- Castle T, Amador M, Rawlins S, Figueroa JP, Reiter P. Absence of impact of aerial malathion treatment on Aedes aegypti during a dengue outbreak in Kingston, Jamaica. Rev Panam Salud Pública 1999; 5:100-5.

28.- Strobel M, Lamaury I. Dengue fever: a review. Rev Med Interne 2001; 22:638-47.

29.- Dengue. [en línea] [fecha acceso 12 enero 2004] URL disponible en http://correo.biomedicas.unam.mx/ gmp/ dengue/introduccion.html.

30.- Dengue. [en línea] [fecha acceso 12 enero 2004] URL disponible en http://www.cenave.gob.mx/dengue.

31.- ¿Qué es el Dengue? [en línea] [fecha acceso 12 enero 2004] URL disponible en http://www.cenave.gob.mx/ dengue/default.asp?id=20.

32.- Sosa GL, Sena CA, Ramírez HM, Alegre GB. Dengue: "Un problema emergente" Revista de Postgrado de la VIa Cátedra de Medicina, 2002 N$^{\circ} 122$ \&\#8211: 10-17.

33.- Fruttaldo L, Schettino G, Mongio F, Gatti G, Deambrogio V. A case of dengue from Pune, India. J Travel Med 2000; 7:46-7.

34.- Henchal EA, Putnak JR. The Dengue viruses. Clin Microbiol Rev 1990; 3:376-96.

35.- Leitmeyer KC, Vaughn DW, Watts DM, Salas R, Villalobos I, de Chacon, et al. Dengue virus structural differences that correlate with pathogenesis. J Virol 1999; 73:4738-47).

36.- Sáenz E, Víquez M, Lara J, Espinosa E, Vargas L, Gamboa F. El laboratorio en el diagnóstico del Dengue. Unidad de Inmunología y RIA, INCIENSA, Ministerio de Salud.

37.- Valle RP, Falgout B. Mutagenesis of the NS3 Protease of Dengue Virus Type 2. J Virol 1998; 72: 624-32.

38.- Estructura del virus y ciclo de vida. [en línea] [fecha acceso 12 enero 2004] URL disponible en http:// bioinformatica.uab.es/biocomputacio/treballs99-00/BasconHernanz/ricky.htm.

39.- Guirakhoo F, Heinz FX, Kuno C. Epitope model of tickborne encephalitis virus envelope glycoprotein E, analysis of structural properties, role of carbohydrate side chain and conformational changes occurring at acidic $\mathrm{pH}$. Virology, 1989; 169:90-9.

40.- Heinz FX, Roehrig JT. Flaviviruses, En (Van Regenmortel MHV, Neurath AR) "Immunochemestry of viruses. II. The basis for serodiagnosis and vaccines". Amsterdam: Elsevier; 1990. p. 289-306.

41.- Mandl CW, Guirakhoo F, Holzmann H, Heinz FX, Kunz C. Antigenic structure of the flavivirus envelope protein $\mathrm{E}$ at the molecular level, using tick borne encephalitis virus as a model. J Virol 1989; 63:564-71.

42.- Pryor MJ, Wright PJ. Glycosylation mutants of Dengue virus NS1 protein. J Gen Virol 1994; 75:1183-7.

43.- Pletnev AG, Pletnev AG, Bray M, Lai CJ. Chimeric tickborne encephalitis and Dengue type 4 viruses: effects of mutations on neurovirulence in mice. J Virol 1993; 67:495663. 


\section{CAcosta-Bas, I Gómez-Cordero.}

44.- Parrish CR, Woo WS, Wrigth PJ. Expression of the NS1 gene of Dengue virus type using vaccinia virus. Dimerization of the NS1 glyprotein. Arch Virol 1991; 117:279-86.

45.- Schlesinger JJ, Brandriss MW, Putnak JR, Walsti EE. Cell surface expression of yellow fever virus non-structural glycoprotein NS1: consequences of interaction with antibody. J Gen Virol 1990; 71: 593-9.

46.- Henchal EA, Henchal LS, Thaisombonsuk BK. Topological mapping of unique epitopes on the Dengue 2 virus NSI protein using monoclonal antibodies. J Gen Virol 1987; 68:845.

47.- Putnak RJ, Charles PC, Padhmanaban R, Irie K, Hokz $\mathrm{CH}$, Burke DS. Functional and antigenic domains of the Dengue 2 virus non structural glycoprotein NS1. ViroIogy 1988; 163:93.

48.- Falconar AK, Young PR. Immunoaffinity purification of native dimer forms of the flavivirus non-structural glycoprotein NSI. J Virol Methods 1990; 30:323-32.

49.- Cauchi MR, Henchal EA, Wright PJ. The sensitivity of cell-associated dengue virus proteins to trypsin and the detection of trypsin-resistant fragments of the nonstructural glycoprotein NS1. Virology 1991; 80:659-67.

50.- Fan WF, Mason PW. Membrane association and secretion of the Japanese encephalitis virus NSI protein from cells expressing NSI cDNA. Virology 1990; 177:470-6.

51.- Coia G, Parker MD, Speight G, Byrne NIE, Westaway EG. Nucleotide and complete aminoacid sequences of Kunjin virus: definitive gene order and characteristics of the virusspecified proteins. J Gen Virol 1988; 69:1.

52.- Huang JH, Wey JJ, Sun YC, Chin C, Chien LJ, Wu YC. Antibody responses to an immunodominant nonstructural 1 synthetic peptide in patients with Dengue fever and Dengue hemorrhagic fever. J Med Virol 1999; 57:1-8.

53.- García G, Vaughn DWE, Del Angel AM. Recognition of synthetic oligopeptides from non structural proteins NS1 and NS3 of Dengue 4 virus by sera from Dengue virusinfected children. Am J Trop Med Hyg 1997; 56:466.

54.- Preugschat F, Strauss JH. Processing of nonstructural proteins NS4A and NS4B Dengue 2 virus in vitro and in virus. Virology 1991; 185:689-97.

55.- Falgout B, Pethel M, Zhang MX, Lai CJ. Both nonstructural proteins NS2B and NS3 are require for the Revista Biomédica proteolytic processing of Dengue virus nonstructural proteins. J Virol 1991; 65:2467-75.

56.- Wengler G. The NS3 nonstructural protein of flaviviruses contains an RNA triphosphatase activity. Virology 1993; 197:265-73.

57.- Gubler DJ. Dengue. En: TP Monath, editor. The arboviruses: Epidemiology and ecology. Boca Ratón: CRC Press, Inc; 1989. p. 223-60.

58.- Churboonchart V, Bhamarapravati N, Peampramprecha $\mathrm{S}$, Sirinavin S. Antibodies against Dengue viral proteins in primary and secondary Dengue hemorragic fever. Am J Med Hyg 1991; 44:481.

59.- Rey FA, Heinz FX, Mand L, Hamson JC. The envelope glycoprotein from tick-borne encephalitis virus at 2 resolution. Nature 1995; 375:291-8.

60.- Chambers TJ, Chang S, Hanh RG, Rice CM. Flavivirus genome, organization, expression and replication. Ann Rev Microbiol 1990; 44:649-88.

61.- Deubel V. Recents advances and prospective researches on molecular epidemiology of Dengue viruses. Mem Inst Oswaldo Cruz 1992; 87 (Supl 5):133-6.

62.- Mason PW, Zügel MU, Semproni AR, Fournier MJ, Mason TL. The antigenic structure of Dengue type 1 virus envelope and NS1 proteins expressed in Escherichia coli. J Gen Virol 1990; 711:2107-14.

63.- Mégret F, Martin A, Hugnot PJ, Ehret C, Van Regenmortel MHV, Deubel V. Identification and expression of antigenie domains of the E glycoprotein of Dengue viruses, in: Immuneresponses to proteins with recombinant epitopes. Protection for vaccines Conf. Ph. Laudat, IN-SERM Strasbourg; 1990. p. 215.

64.- Margalit H, Spouge J, Cornette J, Cease K, Delisi C, Berzofsky J. Prediction of immunodominant helper T cell antigenic sites from the primary sequence. J Immunol 1987; 138:2213-29.

65.- Roehrig JT, Hunt AR, Jolinson A.J, Hawkes R.A. Synthetic peptides derived from the deduced aminoacid sequence of the E glycoprotein of Murray Valley encephalitis virus elicit antiviral antibody. Virology 1989; 171:49-60.

66.- Scott H. Dengue. Aspectos clínicos y etiopatogenia. Exposiciones de Taller Dengue en la UCV. Temas para el médico. [en línea] 2004 [fecha acceso 20 febrero 2004] URL 


\section{Biología y diagnóstico del dengue.}

disponible en http://www.reinaldogodoyeditor.com/ subpaginas/tallerdengue.htm.

67.- Kubelka C. Febre do Dengue e Dengue Hemorrágico. [en línea] 2002 [fecha acceso 10 marzo 2004] URL disponible en http://www.sbi.org.br/sbinarede/SBInarede5/ dengue.htm

68.- Situation of Dengue/Dengue Haemorrhagic Fever in the South-East Asia Region. [en línea] 2001 [fecha acceso 20 febrero 2004] URL disponible en http://w3. whosea.org/ dengue/introduction.htm.

69.- Comach G, Alvarez M, Camacho D, Chiarello A, de Quintana M, Soler M, et al. Utilidad de la transcripción reversa-reacción en cadena de la polimerasa (RT-PCR) para la vigilancia proactiva y el diagnóstico clínico del dengue. Boletín de malariología y saneamiento ambiental, 2001, XLI(1 y 2).

70.- Nisalak A, Endy TP, Nimmannitya S, Kalayanarooj S, Thisayakorn U, Scott RM, et al. Serotype-specific dengue virus circulation and dengue disease in Bangkok, Thailand from 1973 to 1999. Am J Trop Med Hyg 2003; 68:191-202.

71.- WHO Classification of Dengue Fever. [en línea] [fecha acceso 20 marzo 2004] URL disponible en http:// www.cdc.gov.

72.- Dengue: aspectos clínicos y de salud pública. Sección de enfermedades infecciosas transmitidas por vectores. [en línea] [fecha acceso 20 marzo 2004] URL disponible en http:/ /www.cdc.gov/ncidod/dvbid/dengue/slideset/spanish/ set1/i/slide08.htm.

73.- Méndez A, González G. Dengue haemorrhagic fever in children: ten years of clinical experience. Biomedica 2003; 23:180-93.

74.- Agarwal R, Kapoor S, Nagar R, Misra A, Tandon R, Mathur A, et al. A clinical study of the patients with dengue hemorrhagic fever during the epidemic of 1996 at Lucknow, India. J Trop Med Public Health 1999; 30:735-40.

75.- Inmunopatología (Grupo de consenso nacional para la prevención y control del dengue en Venezuela). Dengue: Manual Práctico. [en línea] 2001 [fecha acceso 20 marzo 2004] URL disponible en http:// www.reinaldogodoyeditor.com/subpaginas/ manualDengue.htm.

76.- Aspectos Clínicos y Diagnósticos de la Fiebre por Dengue y Dengue Hemorrágico. Criterios de definición de
Casos, según OPS/OMS, 2001.

77.- 2003: Number of Reported Cases of Dengue \& Dengue Hemorrhagic Fever (DHF), Region of the Americas (by country and subregion), 2004.

78.- Crespo MP. El diagnóstico viral por el laboratorio. Colombia Médica 2000; 31:135-50.

79.- Vaughn DW, Green S, Kalayanarooj S, Innis BL, Nimmannitya S, Suntayakorn S, et al. Dengue in the early febrile Phase: Viremia and antibody responses. J Infect Dis 1997; 176:322.

80.- Ashburn PM, Craig CF. Experimental investigation regarding the etiology of Dengue fever. J Infect Dis 1970; 4:440.

81.- Kuberski T, Rosen L, Reed D, Mataika J. Clinical and laboratory observations on patiens with primary and secondary Dengue type 1 infections with hemorrhagic manifestation in Fiji. Am J Trop Med Hyg 1977; 26:775-83.

82.- Guzmán MG, Kourí G. Advances in dengue diagnosis. Clin Diag Lab Immunol 1996; 3:621-7.

83.- Guzmán MG. Avances en el diagnóstico del dengue y su utilidad para el turista Asociación Médica del Caribe. [en línea] 2000 [fecha acceso 15 febrero 2004] URL disponible en http://www.ameca.cu/biblioteca/ avanceseneldiasnog.html.

84.- Malergue F, Chungue E. Rapid and sensitive streptavidin-biotin amplified flurogenic enzyme-linked immunosorbent-assay for direct detection and identification of Dengue viral antigens in serum. J Med Virol 1995; 47:437.

85.- Yamada K, Takasaki T, Nawa M, Kurane I. Virus isolation as one of the diagnostic methods for dengue virus infection. J Clin Virol 2002; 24:203-9.

86.- Guzmán MG. Avances en el diagnóstico del dengue. Exposiciones de Taller Dengue en la UCV. Temas para el médico. [en línea] 2004 [fecha acceso 20 febrero 2004] URL disponible en http://www.reinaldogodoyeditor.com/ subpaginas/tallerdengue.htm.

87.- Balmaceda A. Manual de procedimientos de técnicas para el diagnóstico del Dengue. Programa de Reconstrucción Pos-Huracanes George y Mitch. Organización Panamericana de la Salud, Oficina Regional de la Organización Mundial de la Salud, 2002. 


\section{Acosta-Bas, I Gómez-Cordero.}

88.- World Health Organization. Dengue haemorrhagic fever: diagnosis, treatment, prevention and control, 2nd edition. World Health Organization, Geneva, Switzerland, 1997, 3447.

89.- Simmon JS, St. John JH, Reynols FHK. Experimental studies of Dengue. Philippine J Sci 1931;44:1.

90.- Russell PK, Brandt WE. Immunopathologic processes and viral antigens associated with sequential Dengue virus infection. En Pollard M. editor."Perspectives in virology" New York: Academic Press; 1973. p. 263.

91.- Whitehead RH, Chaicumpa V, Olson L, Russell PK. Sequential Dengue virus infection of white-handed gibbon (Hylobates lar). Am J Trop Med Hyg 1970; 19:94-102.

92.- Innis BL, Nisalak A, Nimmannitya S, Kusalerdchariya S, Chongswadi V, Suntakorn S, et al. An enzyme-linked immunosorbent assay to characterize Dengue infections where Dengue and Japanese ancephalitis co.circulate. Am J Trop Med Hyg 1989; 40:418-27.

93.- Ruechusatsawat KK, Morita M, Tanaka S, Vongcheree $\mathrm{S}$, Rojanasuphot $\mathrm{P}$, Warachit $\mathrm{K}$, et al. Igarashi. Daily observation of antibody levels among Dengue patiens detected by enzyme-linked immunosorbent assay (ELISA). J Trop Med Hyg 1994; 22:9.

94.- Cuzzubbo AJ, Vaughn DW, Nisalak A, Suntayakorn S, Aaskov J, Devine PL. Detection of specific antibodies in saliva during Dengue infection. J Clin Microbiol 1998; 36:3737-9.

95.- Talarmin A, Labeau B, Lelarge J, Sarthou JL. Immunoglobulin A specific capture enzyme-linked immunosorbent assay for diagnosis of Dengue fever. J Clin Microbiol 1988; 36:1189.

96.- Camacho DE, Alvarez M, Rodríguez F, de Quintana M, Soler M, Chiarello A, et al. Laboratory diagnosis of dengue virus infections in Aragua State, Venezuela: October 1997December 1998. Invest Clin 2003; 44:91-103.

97.- Sudiro TM, Ishiko H, Green S, Vaughn DW, Nisalak A, Kalayanarooj S, et al. Rapid diagnosis of dengue viremia by reverse transcriptase-polymerase chain reaction using 3'noncoding region universal primers. Am J Trop Med Hyg 1997; 56:424-9.

98.- Vorndam V, Kuno G. Laboratory diagnosis of dengue virus infections. En Gubler DJ, Kuno G. Ed. Dengue and dengue hemorrhagic fever. Wallingford: CAB International
1997. p. 313-34.

99.- Harris E, Roberts TG, Smith L, Selle J, Kramer LD, Valle S, et al. A Typing of dengue viruses in clinical specimens and mosquitoes by single-tube multiplex reverse transcriptase PCR. J Clin Microbiol 1998; 36:2634-9.

100.- Rosario D, Alvarez M, Díaz J, Contreras R, Rodríguez R, Vásquez S, Guzmán MG. Reacción en cadena de la polimerasa para la detección rápida y determinación del serotipo del virus del dengue en muestras clínicas. Rev Panam Salud Pública 1998; 4:1-5.

101.- Rigau JG, Clark GG, Gubler DJ, Reiter P, Sanders E, Vorndam AV. Dengue and dengue haemorrhagic fever. Lancet 1998; 352:971-7.

102.- Vorndam V, Beltran M. Enzyme-linked immunosorbent assay-format microneutralization test for dengue viruses. Am J Trop Med Hyg 2002; 66:208-21.

103.- Kittigul L, Suankeow K. Use of a rapid immunochromatographic test for early diagnosis of dengue virus infection. Eur J Clin Microbiol Infect Dis 2002;21:2246.

104.- Parida MM, Upadhyay C, Saxena P, Dash PK, Jana AM, Seth P. Evaluation of a dipstick ELISA and a rapid immunochromatographic test for diagnosis of Dengue virus infection. Acta Virol 2001; 45:299-304.

105.- Shu PY, Chen LK, Chang SF, Yueh YY, Chow L, Chien LJ, et al. Potential application of non structural protein NS1 serotype-specific immunoglobulin $\mathrm{G}$ enzyme-linked immunosorbent assay in the seroepidemiologic study of dengue virus infection: correlation of results with those of the plaque reduction neutralization test. J Clin Microbiol 2002; 40:1840-4.

106.- Wu SJ, Lee EM, Putvatana R, Shurtliff RN, Porter KR, Suharyono W, et al. Detection of dengue viral RNA using a nucleic acid sequence-based amplification assay. J Clin Microbiol 2001; 39:2794-8.

107.- Miagostovich MP, dos Santos FB, Gutierrez CM, Riley LW, Harris E. Rapid subtyping of dengue virus serotypes 1 and 4 by restriction site-specific PCR. J Clin Microbiol 2000; 38:1286-9.

108.- Cuzzubbo AJ, Endy TP, Nisalak A, Kalayanarooj S, Vaughn DW, Ogata SA, et al. Use of recombinant envelope proteins for serological diagnosis of Dengue virus infection in an immunochromatographic assay. Clin Diagn Lab

\section{Revista Biomédica}


Immunol 2001; 8:1150-5.

109- Lam S, Lan Ew C, Mitchell JL, Cuzzubbo AJ, Devine PL. Evaluation of a capture screening enzyme-linked immunosorbent assay for combined determination of immunoglobulin $\mathrm{M}$ and $\mathrm{G}$ antibodies produced during Dengue infection. Clin Diagn Lab Immunol 2000; 7:850-2.

110.- Vaughn DW, Nisalak A, Solomon T, Kalayanarooj S, Nguyen MD, Kneen R, et al. Rapid serologic diagnosis of dengue virus infection using a commercial capture ELISA that distinguishes primary and secondary infections. Am J Trop Med Hyg 1999; 60:693-8.

111.- Palmer CJ, King SD, Cuadrado RR, Perez E, Baum M, Ager AL. Evaluations of the MRL diagnostics dengue fever virus IgM capture ELISA and the PanBio Rapid Immunochromatographic Test for diagnosis of dengue fever in Jamaica. J Clin Microbiol 1999; 37:1600-1.

112.- Cardosa MJ, Baharudin F, Hamid S, Tio Phaik H, Nimmanitya S. A nitrocellulose membrane based IgM capture enzyme immunoassay for etiological diagnosis of Dengue virus infections. Clin Diagn Virol 1995; 3:343.

113.- Wu SJL, Hanson B, Paxton H, Nisalak A, Vaughn DW, Rossi C, et al. Evaluation of a dipstick enzyme-linked immunosorbent assay for detection of antibodies to Dengue virus. Clin Diagn Lab Immunol 1997; 4:452-7.

114.- Roehrig JT, Johnson AJ, Hunt AR, Bolin RA, Chu MC. Antibodies to Dengue 2 virus E-glycoprotein synthetic peptides identify antigenic conformation. Virology 1990; 177:668-75.

115.- Stephenson JR, Crooks AJ, Lee JM. The synthesis of immunogenic polypeptides encoded by tick-borne encephalitis virus. J Gen Virol 1987; 68:1307-16. 